\title{
Acidogenesis is a key step in the anaerobic biotransformation of organic micropollutants
}

Rodrigo B. Carneiro, Lorena Gonzalez-Gil, Yudy Andrea Londoño, Marcelo Zaiat, Marta Carballa, Juan M. Lema

\section{Accepted Manuscript}

\section{How to cite:}

Journal of Hazardous Materials, 389 (2020), 121888.

https://doi.org/10.1016/i.jhazmat.2019.121888

\section{Copyright information:}

(C) 2019 Elsevier B.V. This manuscript version is made available under the CC-BY-NC-ND 4.0 license (http://creativecommons.org/licenses/by-nc-nd/4.0/) 


\section{HIGHLIGHTS}

- Acidogenesis and not hydrolysis sets the fate of OMPs during anaerobic digestion

- Biotransformation is the main mechanism for the acidogenic removal of OMPs

- Acidogenic enzymes and the molecular structure of OMPs drive biotransformation

- Acidogenic conditions favored the biotransformation of musks and macrolides 


\section{Acidogenesis is a key step in the anaerobic biotransformation of organic}

2 micropollutants

3

4 Rodrigo B. Carneiro ${ }^{1,2, a, *}$, Lorena Gonzalez-Gil ${ }^{1, a}$, Yudy Andrea Londoño ${ }^{3}$, Marcelo

5 Zaiat $^{2}$, Marta Carballa ${ }^{1}$, Juan M. Lema ${ }^{1}$

6

$7 \quad{ }^{1}$ Department of Chemical Engineering, School of Engineering, Universidade de

8 Santiago de Compostela, Rúa Lope Gómez de Marzoa, E-15782 Santiago de

9 Compostela, Spain

$10{ }^{2}$ Department of Hydraulics and Sanitation, São Carlos School of Engineering,

11 University of São Paulo, Av. Trabalhador São Carlense, 400, 13566-590 São Carlos,

12 SP, Brazil

$13{ }^{3}$ GDCON Research Group, Faculty of Engineering, University Research Headquarters

14 (SIU), University of Antioquia, Street 70 \# 52-21, Medellín, Colombia

15

$16{ }^{a}$ Equally contributed to the work.

17 * Corresponding author:

18 Email: rodrigocarneiro@sc.usp.br; Phone: +55 (16) 3373-8357 / 3373-8358

19

20 Declarations of interest: none. 
21 Abstract: Understanding the role of the different anaerobic digestion stages on the

22 removal of organic micropollutants (OMPs) is essential to mitigate their release from

23 wastewater treatment plants. This study assessed the fate of 21 OMPs during hydrolysis

24 and acidogenesis to elucidate the contribution of these stages to the overall anaerobic

25 removal. Moreover, the removal mechanisms and factors influencing them were

26 investigated. To this purpose, a fermentation reactor was operated and fed with two

27 different substrates: starch (to jointly evaluate hydrolysis and acidogenesis) and glucose

28 (to isolate acidogenesis). Results indicate that sulfamethoxazole was highly

29 biotransformed (>80\%), while galaxolide, celestolide, tonalide, erythromycin,

30 roxithromycin, trimethoprim, octylphenol and nonylphenol achieved a 50-80\%

31 biotransformation. Since no significant differences in the biotransformation efficiencies

32 were found between starch and glucose fermentation, it is stated that the enzymatic

33 activities involved in starch hydrolysis do not significantly contribute to the cometabolic

34 biotransformation of OMPs, while acidogenesis appears as the major player. Moreover,

35 a higher biotransformation $(\geq 15$ percentage points and $p \leq 0.05)$ was found for

36 galaxolide, celestolide, tonalide, erythromycin and roxithromycin during acidogenesis

37 in comparison with the efficiencies reported for the acetogenic/methanogenic step. The

38 biotransformation of some OMPs was explained considering their chemical structure

39 and the enzymatic activities.

40 Keywords: Biodegradation, Hydrolysis, Fermentation, Methanogenesis, Partition

41 coefficient. 


\section{INTRODUCTION}

43 The presence of organic micropollutants (OMPs) in effluents from wastewater treatment 44 plants (WWTPs) has been a growing concern as these compounds pose a threat to

45 public health, biota and the economy, making drinking water treatment more expensive. These OMPs comprise pesticides, industrial chemicals, components of consumer products, pharmaceuticals, personal care products, hormones, and other organic pollutants that are ubiquitous in sewage and other environmental samples [1-3]. Their concentrations in the environmental matrices are quite variable, and the untreated wastewater concentrations (e.g. up to $2 \mu \mathrm{g} \cdot \mathrm{L}^{-1}$ of sulfamethoxazole, $9 \mu \mathrm{g} \cdot \mathrm{L}^{-1}$ of musks, 1 $\mu \mathrm{g} \cdot \mathrm{L}^{-1}$ of estrone and $5 \mu \mathrm{g} \cdot \mathrm{L}^{-1}$ of triclosan) are usually smaller than those found in sewage sludge (e.g. up to $18 \mu \mathrm{g} \cdot \mathrm{L}^{-1}$ of sulfamethoxazole, $141 \mu \mathrm{g} \cdot \mathrm{L}^{-1}$ of musks, $8 \mu \mathrm{g} \cdot \mathrm{L}^{-1}$ of estrone and $38 \mu \mathrm{g} \cdot \mathrm{L}^{-1}$ of triclosan) [4-6]. Understanding the distribution, fate, and behavior of these OMPs in biological treatments is a prerequisite to optimizing their elimination in WWTPs [7].

The main mechanisms involved in the biological removal of OMPs in WWTPs comprise sorption on the biomass and biotransformation through cometabolism [8-12]. Several factors may influence these mechanisms: physicochemical properties of each compound (hydrophobicity - octanol-water partitioning coefficient, charge - anionic or cationic form, and functional groups - presence of electron donating groups or withdrawing groups - EDGs or EWGs); operational conditions of the treatment system (sludge retention time, $\mathrm{pH}$ and temperature); redox conditions (anaerobic, anoxic and aerobic); diversification and adaptation of the microbial communities involved in the process; and presence of specific microbial enzymes [1,13-18]. For instance, recent studies have indicated that anaerobic systems can enhance the biodegradation of some OMPs, notably sulfamethoxazole, trimethoprim and naproxen [6,13,16,19-22], possibly 
67 due to the negative redox potential of the environment and the presence of specific

68 microorganisms and enzymes.

69 Anaerobic treatment is widely applied worldwide in several ways: as a main secondary

70 treatment unit in tropical countries - e.g., UASB (Upflow Anaerobic Sludge Blanket)

71 reactors [23]; digestion of primary and secondary sewage sludge; and as a preliminary

72 unit in activated sludge plants that require a biological phosphorus removal [24].

73 Moreover, anaerobic conditions frequently occur in environmental matrices, such as

74 soils, sediments, groundwater and landfills $[25,26]$. In all these natural environments

75 and engineering applications, anaerobic digestion usually occurs through four main

76 biological stages, namely hydrolysis, acidogenesis, acetogenesis and methanogenesis,

77 which are catalyzed by different microbial populations and enzymes. Many studies have

78 reported removal efficiencies of OMPs in anaerobic systems [6,13,14,16,20,27-35],

79 however research on the capacity of the four biological stages to degrade OMPs is still

80 incipient, and most microorganisms, enzymatic processes, and anaerobic

81 biotransformation pathways remain unknown [15]. A recent study performed by

82 Gonzalez-Gil et al. [36] investigated the contribution of acetogenesis-methanogenesis to

83 the OMP biotransformation during anaerobic digestion. However, the role of hydrolysis

84 and acidogenesis is completely unexplored. It is expected that during these stages,

85 several OMPs will be biotransformed, since hydrolytic microbes/enzymes are usually

86 less specific and sensitive to the input of toxic xenobiotic compounds than

87 methanogenic ones [37]. Furthermore, some authors [38-40] indicated that fermentative

88 microorganisms are able to use organic compounds containing aromatic rings as

89 electron acceptors (e.g. benzene, xylene, benzoate, phenol, and polycyclic aromatic

90 hydrocarbons), and thus a similar behavior could be hypothesized for aromatic OMPs. 
91 Actually, Duan et al. [41] recently proved that the surfactant nonylphenol is

92 biotransformed under acidogenic stages.

93 The metabolic routes during hydrolysis and acidogenesis depend on the substrate

94 composition. Carbohydrates are among the main constituents of various agroindustrial

95 waste, municipal sewage and sewage sludge that are treated anaerobically $[42,43]$.

96 Besides, carbohydrates are the preferred substrate for fermentative hydrogen-producing

97 bacteria such as Clostridium species (sp.) [44] and they were more efficiently and

98 rapidly degraded than proteins during sludge anaerobic digestion [45]. In addition, their

99 metabolic routes are well known, and glycolysis is an obligatory route for the pyruvate

100 formation with the sequential generation of soluble fermentation products [46].

101 In this context, the main objective of this study is to assess the role of (starch-

102 )hydrolysis and (glucose-)acidogenesis on the anaerobic biotransformation of 21 OMPs.

103 To this aim, the fate of OMPs in a fermentative reactor was evaluated; in particular, the

104 mechanisms responsible for removing OMPs (i.e., biotransformation, sorption and

105 abiotic reactions) and the main factors (e.g., chemical structure, partition coefficient and

106 enzymatic activities) driving biotransformation were investigated. Finally, attempting to

107 set the relevance of hydrolysis/acidogenesis versus acetogenesis/methanogenesis to the

108 biotransformation of OMPs during the overall anaerobic digestion process, our

109 experimental results were compared with bibliographic data from an

110 acetogenic/methanogenic reactor [36].

\section{2. MATERIALS AND METHODS}

\section{2.1. Hydrolytic/Acidogenic reactor}

113 An anaerobic lab-scale (5 L) reactor was operated under mesophilic $\left(37^{\circ} \mathrm{C}\right)$ and acidic

114 ( $\mathrm{pH}$ of $5.0 \pm 0.2$ ) conditions. Based on the studies performed by Temudo et al. [46] and

115 Regueira et al. [47], the highest biohydrogen $\left(\mathrm{H}_{2}\right)$ yields were reached at $\mathrm{pH} 5$ during 
116 glucose fermentation by mixed culture. The $\mathrm{pH}$ was controlled by $\mathrm{NaOH}\left(1.0 \mathrm{~mol} \cdot \mathrm{L}^{-1}-\right.$

117 dosage of around $\left.20 \mathrm{~mL} \cdot \mathrm{d}^{-1}\right)$ and $\mathrm{HCl}\left(0.1 \mathrm{~mol} \cdot \mathrm{L}^{-1}-\right.$ dosage of around $\left.5 \mathrm{~mL} \cdot \mathrm{d}^{-1}\right)$ dosing

118 pumps linked to an online monitoring $\mathrm{pH}$ probe. The reactor was inoculated with

119 biomass from a mesophilic sewage sludge digester and it was operated semi-

120 continuously by once-a-day manual feeding and withdrawal of $1.25 \mathrm{~L}$. To keep a high

121 biomass concentration inside the reactor, a settling time of around 15 min was

122 established before withdrawing the effluent. During the whole operation, the organic

123 loading rate was kept at $3.1 \mathrm{~g} \mathrm{COD} \cdot \mathrm{L}^{-1} \cdot \mathrm{d}^{-1}[48]$ and the hydraulic retention time at $4 \mathrm{~d}$

124 [49]. The acidic $\mathrm{pH}$ hindered the methanogenic activity and no methane was detected in

125 the biogas.

126 The reactor operation was divided into two periods depending on the carbon source. In

127 the first period, a complex carbohydrate (i.e., soluble starch, Sigma-Aldrich) was

128 selected to study the combined effect of hydrolysis and acidogenesis on the

129 biotransformation of OMPs. In the second period, the main substrate was the

130 monosaccharide glucose (Sigma-Aldrich) to avoid hydrolysis, and thus to specifically

131 determine the contribution of acidogenesis. Apart from the carbon source $(12.5 \mathrm{~g}$

$132 \mathrm{COD} \cdot \mathrm{L}^{-1}$ of starch or glucose) and the 21 OMPs, the synthetic feeding consisted of

133 macro and micronutrients, based on Angelidaki and Sanders [50], as detailed in Table

134 S1.

136 2.2. Selected organic micropollutants and sampling campaigns

137 The 21 OMPs selected for this study comprise four antibiotics: sulfamethoxazole

138 (SMX), trimethoprim (TMP), erythromycin (ERY) and roxithromycin (ROX); three

139 musk fragrances: galaxolide (HHCB), tonalide (AHTN) and celestolide (ADBI); three

140 anti-inflammatories: ibuprofen (IBP), naproxen (NPX) and diclofenac (DCF); four 
141 neurodrugs: fluoxetine (FLX), carbamazepine (CBZ), diazepam (DZP) and citalopram

142 (CTL); four endocrine disrupting compounds from daily life products: bisphenol A

143 (BPA), triclosan (TCS), 4-octylphenol (OP) and 4-nonylphenol (NP); and three

144 estrogens: estrone (E1), 17 $\beta$-estradiol (E2) and 17 $\alpha$-ethinylestradiol (EE2). The

145 physicochemical characteristics of these compounds are very diverse, as shown in Table

146 S2 of the supplementary material, and they are usually present in sewage sludge at

147 varying concentrations. Therefore, based on the occurrence reported by Verlicchi et al.

148 [51], Tran et al [5] and Clara et al. [52], the spiked concentrations were divided into

149 four groups to obtain a realistic feeding mixture: $1 \mu \mathrm{g} \cdot \mathrm{L}^{-1}$ of estrogens (E1, E2, EE2),

$15040 \mu \mathrm{g} \cdot \mathrm{L}^{-1}$ of musk fragrances (HHCB, AHTN, ADBI), $20 \mu \mathrm{g} \cdot \mathrm{L}^{-1}$ of endocrine

151 disrupting compounds (BPA, TCS, OP, NP) and $10 \mu \mathrm{g} \cdot \mathrm{L}^{-1}$ of the other OMPs (SMX,

152 TMP, ERY, ROX, IBP, NPX, DCF, FLX, CBZ, DZP, CTL). Some recent studies

$153[53,54]$ have pointed that, depending on the applied concentration, the OMPs could

154 either promote or reduce the production of VFA. For instance, increasing the

155 concentration of DCF from $2.5 \mathrm{mg} \cdot \mathrm{kg}^{-1}$ to $25 \mathrm{mg} \cdot \mathrm{kg}^{-1}$ had a positive effect on the

156 reactor acidification performance, while higher doses of DCF (47 $\left.\mathrm{mg} \cdot \mathrm{kg}^{-1} \mathrm{TSS}\right)$

157 decreased the VFA yield [53]. We did not expect a significant effect on the reactor

158 performance at the low OMP concentrations added.

159 Six sampling campaigns were performed in the hydrolytic/acidogenic reactor to

160 measure the OMP concentration in the feeding, the effluent, and the biomass: three

161 campaigns ( 2 samples per campaign, $\mathrm{n}=6$ ) during starch fermentation (hydrolysis +

162 acidogenesis) and three campaigns ( 3 samples per campaign, $n=9$ ) during glucose

163 fermentation (acidogenesis). All the samples were taken on different days, under steady-

164 state conditions (Fig. 1). 


\subsubsection{Conventional parameters}

168 The reactor performance was monitored by physical-chemical analysis in influent,

169 effluent and biomass samples of the reactor, according to the methods described in

170 APHA [55]. The effluent (after biomass settling) and the biomass inside the reactor

171 were analyzed twice a week by duplicate in terms of solids content (total solids (TS),

172 total suspended solids (TSS) and volatile suspended solids (VSS)) and the total and

173 soluble chemical oxygen demand (COD). Samples were taken from the effluent before

174 biomass settling to analyze solids content and COD. The feeding was characterized in

175 terms of COD. The acidification performance of the reactor was monitored twice a

176 week by analyzing the concentration of volatile fatty acids (VFA) - acetic, propionic,

177 butyric, isobutyric, valeric, isovaleric, caproic, isocaproic and heptanoic - in the effluent

178 using a gas chromatograph (HP 5890A) with a Flame Ionization Detector (GC/FID)

179 (HP 7637A). Analysis of glucose, ethanol and formic acid were conducted by high

180 performance liquid chromatography (Agilent 1100 series HPLC). The $\mathrm{pH}$ of the reactor

181 was monitored continuously by a probe (CRISON PH 28). Biogas production was

182 monitored via a Ritter milligascounter (Dr. Ing. Ritter Apparate- bau GmbH, Bochum,

183 Germany) and samples from the headspace of the reactor were occasionally taken to

184 analyze their composition through gas chromatography (HP 5890 Series II) equipped

185 with a thermal conductivity detector (GC-TCD).

\section{2.3.2. Organic micropollutants}

187 The feeding and the effluent samples $(250 \mathrm{~mL})$ were pre-filtered (AP4004705, Milli-

188 pore) and filtered by $0.45 \mathrm{~mm}$ (HAWP04700, Millipore) prior to performing solid phase

189 extraction (SPE) with 60 mg OASIS HLB cartridges (Waters, Milford, MA, USA). The

190 quantification of HHCB, AHTN, ADBI, IBP, NPX, DCF, TCS, NP, OP and BPA was 
191 accomplished using a gas chromatograph (Varian CP-3900) coupled to an ion trap

192 spectrophotometer (Varian CG-2100). The compounds ERY, ROX, SMX, TMP, FLX,

193 CBZ, DZP, CTL, E1, E2 and EE2 were analyzed by a liquid chromatograph (Agilent

194 G1312A) connected to an API 4000 triple quadrupole mass spectrometer (Applied

195 Biosystems). For the determination of OMPs in the solid phase, the biomass from the

196 reactor was lyophilized to obtain approximately $0.5 \mathrm{~g}$ of TSS and subjected to an

197 ultrasonic solvent extraction (USE) process, following a procedure based on Ternes et

198 al. [56]. Three sequential extractions with methanol (4, 4 and $2 \mathrm{~mL})$ and two with

199 acetone (4 and $2 \mathrm{~mL}$ ) were performed on the freeze-dried samples $(0.5 \mathrm{~g})$. After adding

200 the corresponding solvent, samples were ultra-sonicated for $15 \mathrm{~min}$ and then centrifuged

201 at $1500 \mathrm{rpm}$ for $5 \mathrm{~min}$. The resulting supernatants were combined (16 mL), filtered

202 through glass wool, evaporated (TurboVap LV, Biotage) flowing nitrogen (200 kPa,

$20330^{\circ} \mathrm{C}$ ) and resuspended in $100 \mathrm{~mL}$ of Milli-Q water. Finally, SPE with $200 \mathrm{mg}$ OASIS

204 HLB cartridges and OMP quantification were performed as previously described for the

205 liquid phase. Further details about the configuration of the instruments, parameter

206 settings and limits of detection (LOD) and quantification (LOQ) for each OMP (Table

207 S3) are provided in section S3 of the supplementary material.

\section{2.4. COD mass balance and acidification of reactor}

209 An organic mass balance (in $\mathrm{g} \mathrm{COD} \cdot \mathrm{d}^{-1}$ ) in the reactor was performed (Eq. 1 , based on

210 Chernicharo [48]) in order to determine the mass distribution of the input COD that is

211 used for biomass growth and converted into biohydrogen and soluble fermentation

212 products, such as VFA, ethanol and formic acid. The biomass generated in the reactor

213 by anabolism was considered equal to the biomass that is washed from the reactor, since

214 the VSS content remains just about constant throughout each operational period. The 
215 acidification efficiency (\%) of the reactor can be calculated with Eq. 2 (based on

216 Garcia-Aguirre et al. [57]).

$Q_{\text {inf }} \cdot C O D_{\text {inf }}=Q_{\text {eff }} \cdot\left(C O D_{V F A}+C O D_{S F P}+C O D_{V S S}\right)+Q_{g a s} C O D_{H 2}$

Acidification $(\%)=\frac{C O D_{V F A}}{C O D_{\text {inf }}} \cdot 100$

217 where $Q_{i n f}, Q_{e f}$, and $Q_{g a s}$ are the influent, effluent and output gas flows $\left(\mathrm{L} \cdot \mathrm{d}^{-1}\right)$,

218 respectively; $C O D_{\text {inf }}$ is the soluble COD measured in the feeding stream; $C O D_{V F A}$

219 represents the total equivalent COD of VFA measured in the effluent; $C O D_{S F P}$ refers to

220 the COD equivalent in the effluent of other soluble fermentation products, e.g. ethanol

221 and formic acid, calculated by the difference between the COD in the effluent and the

$222 C O D_{V F A} ; C O D_{V S S}$ is the COD equivalent to the washout biomass, based on the

223 experimental biomass growth coefficient ( $Y_{\text {biomass }}$ - Table S4); and $C O D_{H 2}$ represents

224 the COD in the gaseous phase due to biohydrogen. Since $\mathrm{H}_{2}$ was not measured, $C O D_{H 2}$

225 was estimated by Eq. 1 and confirmed by theoretical calculations.

\subsection{Micropollutant removal calculations}

The relevant mechanisms involved in the total anaerobic elimination of OMPs comprise sorption and biotransformation. The total removal of each OMP was calculated by the difference in liquid phase concentration of the influent and effluent of the reactor, according to Yang et al. [18] and Phan et al. [16] (Eq. 3). Thus, to determine the

231 biotransformation efficiency (Eq. 4), it has to be considered that part of the removed

232 OMPs are leaving the reactor sorbed onto effluent solids $\left(C_{\text {sor }}\right.$, Eq. 5). The contribution

233 of sorption to the total removal (Eq. 3) was estimated with Eq. 6. Other parameters

234 usually employed to quantify biotransformation and sorption were also calculated,

235 namely, the pseudo-first order biodegradation constant $\left(k_{\text {biol }}\right.$, Eq. 7 - according to Joss at 
236 al. [58]) and the partition coefficient ( $K_{D}$, Eq. 8 - according to Ternes et al. [59] and

237 Carballa et al. [60]).

Total Removal $(\%)=\frac{C_{\text {inf }}-C_{\text {eff }}}{C_{\text {inf }}} \cdot 100$

$$
=\text { biotransformation }(\%)+\text { sorption }(\%)
$$

Biotransformation $(\%)=\frac{C_{\text {inf }}-\left(C_{\text {eff }}+C_{\text {sor }}\right)}{C_{\text {inf }}} \cdot 100$

$C_{\text {sor }}=C_{S} \cdot T S S_{\text {eff }}$

Sorption $(\%)=\frac{C_{\text {sor }}}{C_{\text {inf }}} \cdot 100$

$k_{\text {biol }}=\frac{\ln \left(\frac{C_{\text {inf }}}{C_{\text {eff }}}\right)}{V S S \cdot H R T}$

$K_{D}=\frac{C_{S} \cdot 1000}{C_{e f f}}$

238 where $C_{\text {inf }}, C_{\text {eff, }} C_{\text {sor }}$ is the concentration $\left(\mu \mathrm{g} \cdot \mathrm{L}^{-1}\right)$ of the OMP in the influent, effluent

239 (dissolved fraction) and sorbed onto effluent solids, respectively; $T S S_{\text {eff }}$ is the total

240 suspended solids in the effluent $\left(\mathrm{g} \cdot \mathrm{L}^{-1}\right) ; C_{S}\left(\mu \mathrm{g} \cdot \mathrm{g}^{-1} \mathrm{TSS}\right)$ is the concentration of OMPs in

241 the solid phase; $k_{\text {biol }}$ is the pseudo-first order biodegradation constant $\left(\mathrm{L} \cdot \mathrm{g}^{-1} \mathrm{VSS} \cdot \mathrm{d}^{-1}\right)$;

242 VSS is the concentration of volatile suspended solids in the reactor $\left(\mathrm{g} \cdot \mathrm{L}^{-1}\right)$; and $K_{D}$ is the

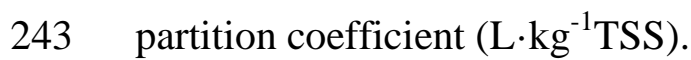

\section{2.6. pH influence on the OMP removal}

245 Abiotic tests (without biomass) were carried out at $\mathrm{pH} 5$ and $\mathrm{pH} 7$ to prove the possible $246 \mathrm{pH}$ effect of the reactor on the elimination of the OMPs. The $\mathrm{pH} 5$ was selected because

247 it was the $\mathrm{pH}$ used in the operation of the hydrolytic/acidogenic reactor, while $\mathrm{pH} 7$ is 
the one usually applied in anaerobic digesters and in conventional biological treatment systems $[48,61]$. In these assays, 3 flasks at each $\mathrm{pH}$ condition (5 and 7) were set up in a buffer spiked with OMPs at the same concentrations as the reactor and kept stirred (150 rpm) at $37{ }^{\circ} \mathrm{C}$ for $72 \mathrm{~h}$. Only the macrolides ERY and ROX showed a decrease in their concentration at $\mathrm{pH}$, which was not found at $\mathrm{pH} 7$. Biotic assays (with acidogenic biomass) were performed to corroborate and estimate the fraction of macrolides biotransformed and abiotically removed by the $\mathrm{pH}$ effect in the reactor. 6 flasks were set up with biomass from the acidogenic reactor $\left(4.8 \mathrm{~g} \mathrm{VSS} \cdot \mathrm{L}^{-1}\right)$ and the synthetic medium (described in Table S1) with $10 \mathrm{~g} \mathrm{COD} \cdot \mathrm{L}^{-1}$ (as starch) spiked with $10 \mu \mathrm{g} \cdot \mathrm{L}^{-1}$ of ERY, ROX, and CBZ (used as no removal control). Then, the $\mathrm{pH}$ was adjusted for two conditions - acid ( $\mathrm{pH} \mathrm{5,} 3$ flasks) and neutral ( $\mathrm{pH}$ 7, 3 flasks). To maintain the $\mathrm{pH}$ during the assay, $\mathrm{KHCO}_{3}$ was used in a ratio of $1.2 \mathrm{~g} \mathrm{KHCO}_{3} \cdot \mathrm{g}^{-1} \mathrm{COD}$. The flasks were kept stirred (150 rpm) at $37{ }^{\circ} \mathrm{C}$ for $96 \mathrm{~h}$. For inhibition of methanogenic archaea, 20 mmol $\cdot \mathrm{L}^{-1}$ of BES (2-Bromoethanesulphonate) was added, according to Silva et al. [62]. The biogas composition in the headspace of the flasks was monitored once a day by gas

263 chromatography (HP 5890 Series II) equipped with a thermal conductivity detector

264 (GC-TCD), and the presence of methane was not detected. In both the abiotic and 265 abiotic assays, OMPs were analyzed at the initial time and after the incubation period, 266 following the procedure detailed in Section 2.3.2.

\subsection{Statistical Analysis}

268 Significant differences between the two operational phases of the reactor - starch and 269 glucose fermentation - were calculated by applying Analysis of Variance (ANOVA) of 270 one factor and Tukey's pairwise test. Likewise, the biotransformation efficiencies of this study were statistically compared with those reported for methanogenesis and 
overall anaerobic digestion. All of the statistical tests were performed at a $5 \%$ significance level by using the statistical software PAST 3.09 [63].

274

\section{RESULTS AND DISCUSSION}

\subsection{Hydrolytic/Acidogenic reactor performance}

277 The reactor was operated under steady-state conditions and presented good acidification performance $(>50 \%)$ throughout both operational periods (starch and glucose fermentation, Fig. 1). Further details of the reactor performance are summarized in Table S4 of the supplementary material. The substrate (starch or glucose) was not detected in the effluent, and approximately $6.5 \%$ was employed for biomass growth.

282 Fig. S1 of the supplementary material shows the COD mass balance and average VFA 283 composition and confirms that most of the substrate has been converted to VFA, and only a small fraction (10-20\%) of the effluent COD corresponds to other soluble fermentation products. Formic acid $(0.3 \%)$ and ethanol $(4.1 \%)$ were detected during the glucose fermentation period. Since $\mathrm{CH}_{4}$ was not detected in the biogas, the remaining

287 COD might correspond to $\mathrm{H}_{2}$. The estimated $\mathrm{H}_{2}$ yield (Table $\mathrm{S} 4$ ) during starch

288 fermentation was $2.7 \mathrm{~mol} \mathrm{H} \cdot \mathrm{mol}^{-1}$ starch, whereas the values reported in the literature are in the range of 0.6 to $3.2 \mathrm{~mol} \mathrm{H}_{2} \cdot \mathrm{mol}^{-1}$ starch [64-66]. During glucose fermentation,

290 the $\mathrm{H}_{2}$ yield $\left(1.7 \mathrm{~mol} \mathrm{H}_{2} \cdot \mathrm{mol}^{-1}\right.$ glucose $)$ was close to that obtained by Fang and Liu [67]

291 (2.1 $\mathrm{mol} \mathrm{H}_{2} \cdot \mathrm{mol}^{-1}$ glucose) and Lin and Chang [68] (1.7 $\mathrm{mol} \mathrm{H}_{2} \cdot \mathrm{mol}^{-1}$ glucose), which 292 also worked with mixed culture in an acidogenic reactor fed with glucose at $\mathrm{pH}$ around

293 5.6. The $\mathrm{H}_{2}$ yields obtained from the COD mass balance (Eq. 1, Table S4) are comparable to the theoretically predicted $\mathrm{H}_{2}$ yields $\left(1.8 \mathrm{~mol} \mathrm{H}_{2} \cdot \mathrm{mol}^{-1}\right.$ starch and $2.3 \mathrm{~mol}$

$295 \mathrm{H}_{2} \cdot \mathrm{mol}^{-1}$ glucose) considering the stoichiometry of the metabolic network and the 296 product spectrum of the reactor [47]. However, it cannot be excluded that part of the 
297 starch is precipitated and not hydrolyzed, which in the COD mass balance would result

298 in an overestimation of the $\mathrm{H}_{2}$ produced (Fig. S1).

299 It should be highlighted that the change of starch by glucose as carbon source led to an

300 increase in the acidification efficiency (from 52\% to $69 \%$ ) and a higher conversion into

301 butyric acid (Fig. S2 - temporal profile of VFA generation). The readily bioavailable

302 glucose concentration is much higher when it is directly fed to the reactor than when it

303 is limited by starch hydrolysis, which could result in a different metabolic pathway [69]

304 and a larger acidification efficiency. It could also be hypothesized that incomplete

305 starch hydrolysis to non-hydrolyzed intermediate polysaccharides could explain the

306 lower acidification efficiency during starch fermentation.

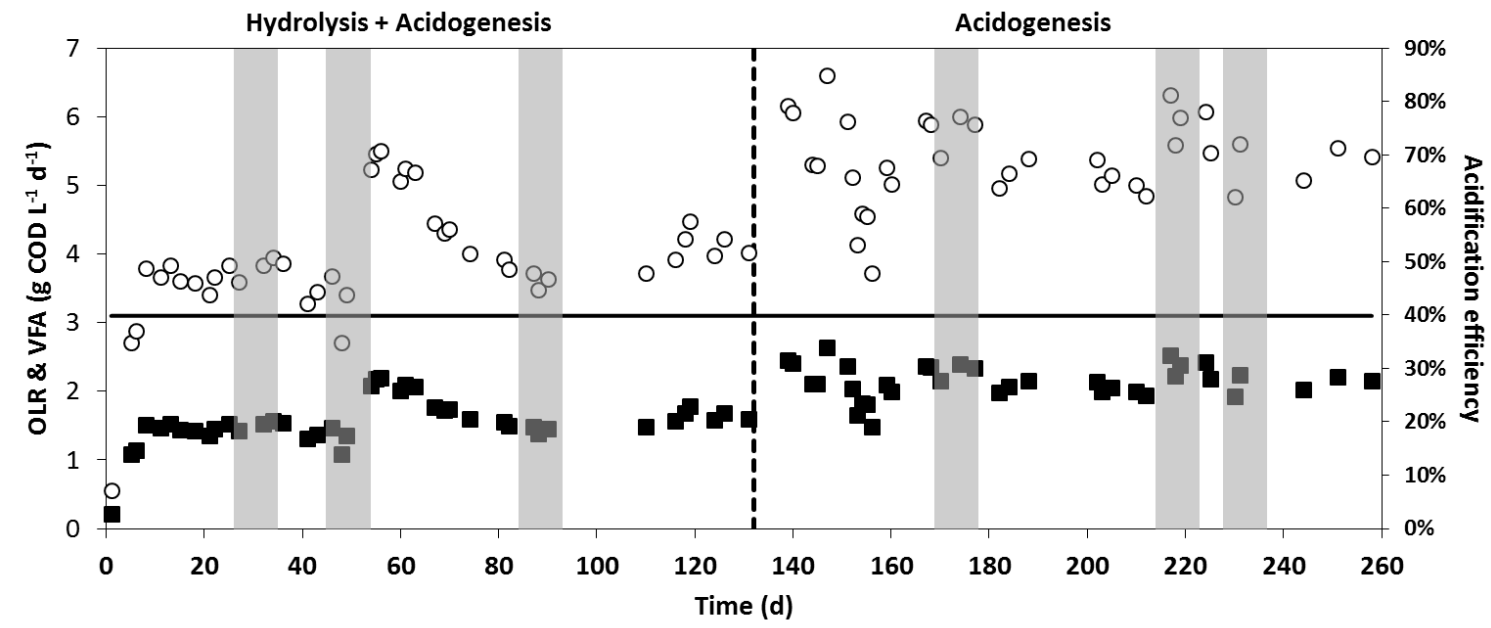

308 Fig. 1. Acidification performance of the reactor during hydrolysis + acidogenesis

309 (starch fermentation) and acidogenesis (glucose fermentation). Grey areas highlight the

310 periods when the OMPs sampling campaigns were conducted.

\section{3.2. Fate of OMPs during hydrolysis/acidogenesis}

313 There are three removal mechanisms influencing the fate of OMPs in the

314 hydrolytic/acidogenic reactor: biotransformation, sorption, and abiotic removal. In 
315 Table S5 of the supplementary material, the biotransformation and sorption results of

316 each operational period (starch and glucose fermentation) are shown. As no significant

317 differences ( $\mathrm{p}>0.05$, and differences below 10 percentage points) were found between

318 both periods, the average contribution of each mechanism to the OMP removal

319 throughout the reactor operation is plotted in Fig. 2. It can be noted that

320 biotransformation is the main mechanism explaining more than half of the total removal

321 observed for all the compounds, except for TCS that was mainly removed by sorption.

322 Sorption was also relevant (> 15\%) in the case of the three musk fragrances (HHCB,

323 AHTN, and ADBI), OP, NP, and FLX. Finally, the abiotic removal at pH 5 was only

324 significantly observed for ERY (40\%). These three removal mechanisms are further

325 discussed in the next sections.

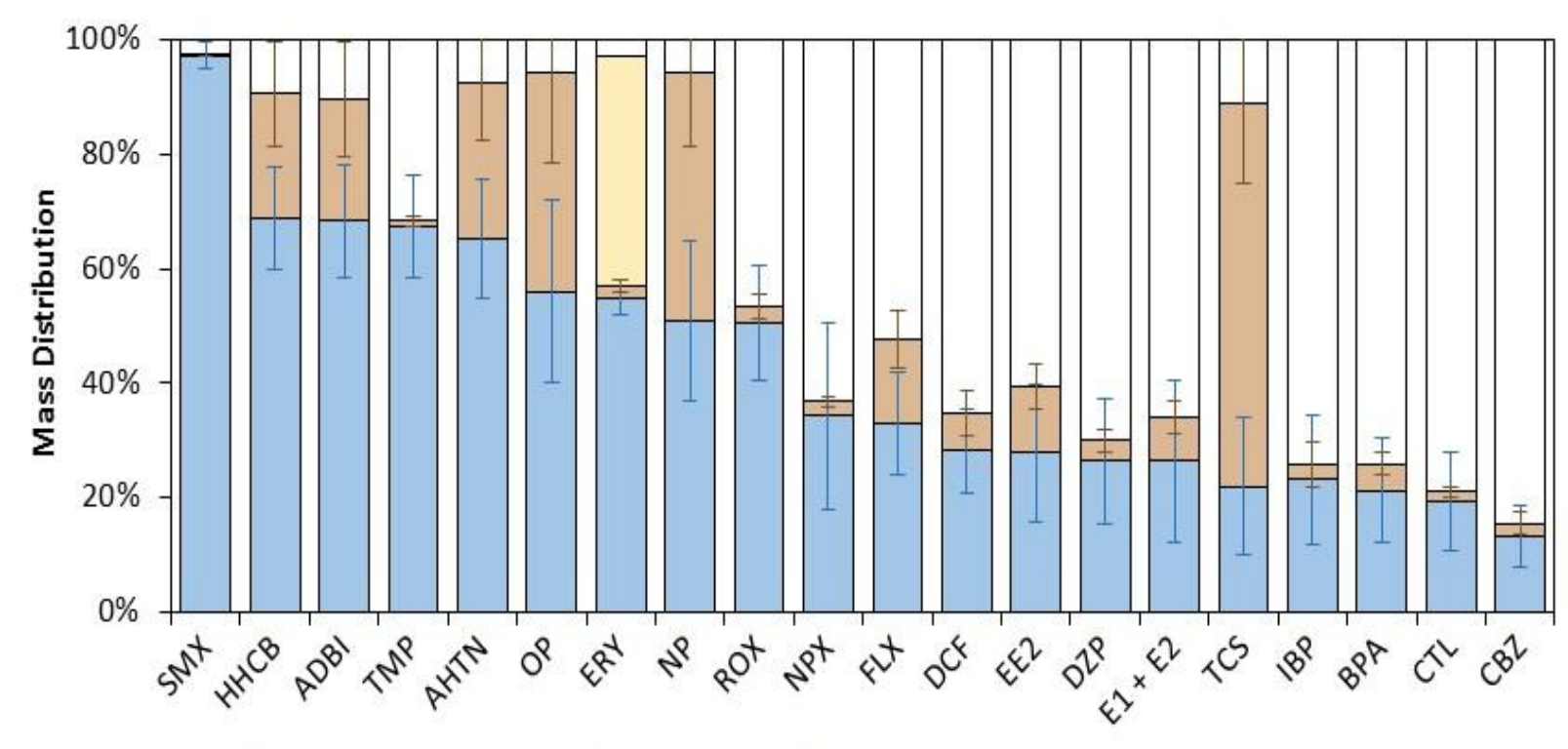

$\square$ Biotransformation $\quad \square$ Sorption $\quad \square$ Abiotic removal $\quad \square$ Remaining in effluent

327 Fig. 2. Fate of OMPs in terms of biotransformation, sorption onto biomass, abiotic

328 elimination and remaining fraction in the effluent. Average values and standard

329 deviations throughout the reactor operation $(n=15)$. 
332 Fig. S3 presents the $\mathrm{pH}$ effect on the elimination of the macrolides ERY and ROX in the

333 biotic and abiotic batch assays. It can be observed that ERY was almost completely

334 removed (95\%) at $\mathrm{pH} 5$ in the abiotic and biotic assays. This behavior agrees with the

335 results of Gobel et al. [70] and Atkins et al [71], who pointed out the chemical

336 instability of ERY under acidic conditions and the formation of the inactive ERY- $\mathrm{H}_{2} \mathrm{O}$.

337 However, in the hydrolytic/acidogenic reactor, biotransformation might occur

338 concomitantly to the abiotic removal. Indeed, when the $\mathrm{pH}$ was set to 7 no abiotic

339 removal was observed and ERY was biotransformed to $55 \%$ in the biotic assays. Since

340 the acidification performance of the biotic assays was similar at pH 5 and 7 (52 and

$34161 \%$, respectively), it is considered that the biomass from the reactor has the same

342 biotransformation capacity at both pHs. Therefore, it is assumed that $55 \%$ of ERY could

343 be biotransformed and the remaining $40 \%$ abiotically removed in the

344 hydrolytic/acidogenic reactor.

345 Regarding ROX, although a slight concentration decrease (15-20\%) was observed at pH

3465 in the abiotic and biotic assays, it was not significant $(\mathrm{p}>0.05)$. Actually, despite

347 ROX and ERY having a similar structure, ROX is more stable under acidic conditions,

348 since this macrolide was specifically synthesized from ERY to avoid its decomposition

349 in the gastric juice [72,73]. As expected, CBZ (negative control) proved to be highly

350 recalcitrant in abiotic and biotic assays and not influenced by the $\mathrm{pH}$.

\subsubsection{Sorption of OMPs}

352 Sorption of OMPs on biomass can be predicted according to the hydrophobicity of the

353 compound $[14,18,74]$, which is estimated by the octanol-water partition coefficient

$354\left(\mathrm{~K}_{\mathrm{ow}}\right)$ (the calculation of the apparent octanol-water partitioning coefficient at $\mathrm{pH}$,

$355 \mathrm{D}_{\mathrm{ow}}$, is detailed in Section S2). Actually, a relationship between the measured sorbed

356 fraction (\%) and the hydrophobicity of each OMP was found, except for FLX, as shown 
357 in Fig. S4 of the supplementary material. Nevertheless, sorption is governed not only by 358 hydrophobicity but also by electrostatic interactions with the sludge [5,16,34], cationic 359 exchanges, cationic bridges, surface complexation and hydrogen bonding [75]. This

360 explains the sorption behavior of FLX, a hydrophilic compound according to its

361 octanol-water partition coefficient but positively ionized at $\mathrm{pH} 5$ (it has basic moieties

362 and a pKa of 9.8 - Table S2), and thus it presented a high sorption potential due to

363 electrostatic interaction with the sludge (negatively-charged) [76]. Since the partition

364 coefficient $\left(\mathrm{K}_{\mathrm{D}}, \mathrm{Eq} .8\right)$ covers all these phenomena, it is considered the best parameter to

365 quantify the solid-liquid distribution of OMPs. According to their $\mathrm{K}_{\mathrm{D}}$ values (Fig. 3),

366 the OMPs were classified into three groups [36]: high sorption ( $\left.\log K_{D} \geq 2.5\right)$, moderate

367 sorption $\left(2.0<\log K_{D} \leq 2.5\right)$; low sorption $\left(\log K_{D} \leq 2.0\right)$. Moreover, in Fig. 3 the average $\mathrm{K}_{\mathrm{D}}$ values obtained in the hydrolytic/acidogenic reactor are compared with the literature range of anaerobic processes (data detailed in Table S6 of supplementary material), revealing a similar sorption behavior.

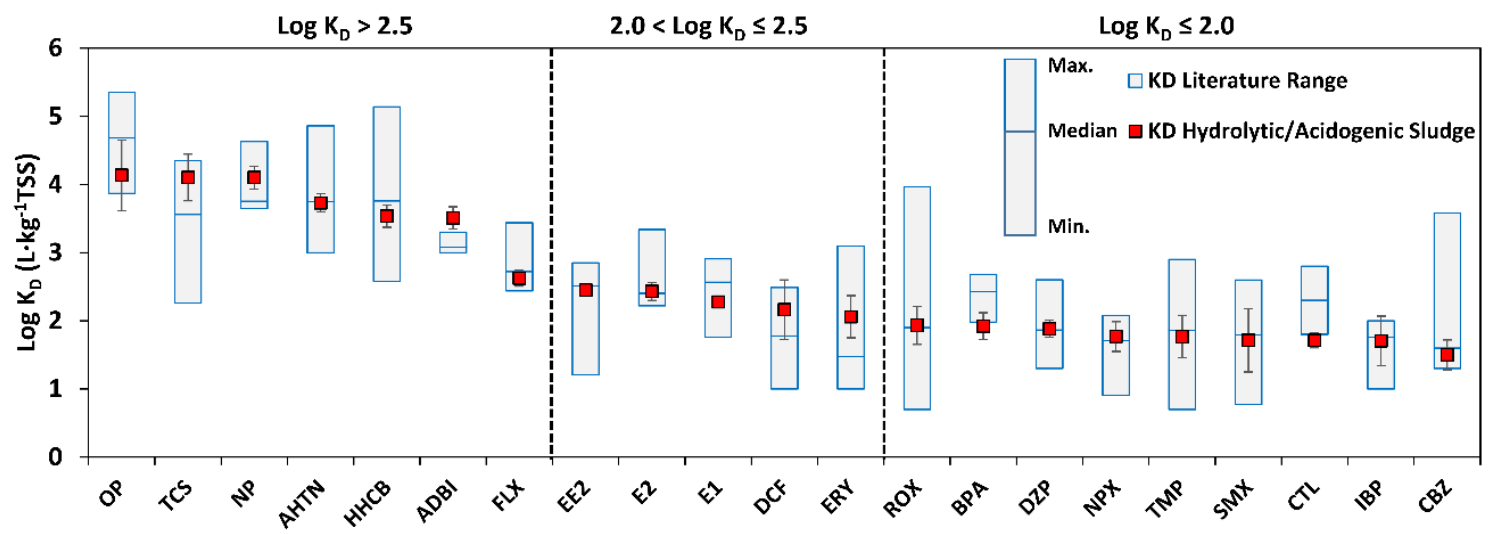

372 Fig. 3. Comparison between the partition coefficient $\left(\log K_{D}-L^{2} \cdot \mathrm{kg}^{-1} \mathrm{TSS}\right)$ in the

373 hydrolytic/acidogenic biomass $(n=15)$ and the literature range for anaerobic sludge (data 374 detailed in Table S6).

\subsubsection{Biotransformation}


The biotransformation efficiencies $(\%)$ and kinetics $\left(k_{b i o l}\right)$ attained in the

377 hydrolytic/acidogenic reactor are presented and compared with the bibliographic results

378 in Fig. 4 and Table S7 of supplementary material, respectively. The OMPs were

379 classified according to their biotransformation in: (i) compounds highly biotransformed

$380 \quad\left(\geq 80 \%\right.$ and $\left.k_{\text {biol }} \geq 0.1 \mathrm{~L} \cdot \mathrm{g}^{-1} \mathrm{VSS} \cdot \mathrm{d}^{-1}\right)-\mathrm{SMX}$; (ii) compounds with a medium

381 biotransformation (50-80\% and $\left.0.04<k_{\text {biol }}<0.1 \mathrm{~L} \cdot \mathrm{g}^{-1} \mathrm{VSS} \cdot \mathrm{d}^{-1}\right)-\mathrm{TMP}$, ADBI, HHCB,

382 AHTN, OP, NP, ROX and ERY; (iii) and OMPs with a moderate-low biotransformation $383\left(\leq 50 \%\right.$ and $\left.k_{\text {biol }} \leq 0.04 \mathrm{~L} \cdot \mathrm{g}^{-1} \mathrm{VSS} \cdot \mathrm{d}^{-1}\right)-\mathrm{NPX}, \mathrm{DCF}, \mathrm{DZP}, \mathrm{TCS}, \mathrm{FLX}, \mathrm{EE} 2, \mathrm{IBP}, \mathrm{E} 1+$

384 E2, CTL, BPA and CBZ.

385 To further understand why different OMPs have different biotransformation

386 efficiencies, we have to consider the molecular structure of the compounds (Table S2)

387 that may exert a great influence. According to Wijekoon et al. [14], compounds containing only EDGs (e.g., $\left.-\mathrm{NH}_{2} ;-\mathrm{NHR} ;-\mathrm{NR}_{2} ;-\mathrm{OH} ;-\mathrm{CH}_{3} ;-\mathrm{OCH}_{3} ; \mathrm{R}-\mathrm{CO}-\mathrm{R}\right)$ could be more susceptible to be anaerobically biotransformed, while those with EWGs (e.g., $-\mathrm{C} \equiv \mathrm{N} ;-\mathrm{CF}_{3} ;-\mathrm{COOH} ;-\mathrm{COOR} ;-\mathrm{COR} ;-\mathrm{Cl} ;-\mathrm{F} ;-\mathrm{CONH}_{2} ;-\mathrm{CHO}$ ) could be more

391 recalcitrant. For instance, the low biotransformation of CBZ observed in the

392 hydrolytic/acidogenic reactor is in agreement with literature data (Fig. 4, Table S8a),

393 and it shows that the presence of the EWG $\left(-\mathrm{CONH}_{2}\right)$ might explain its recalcitrant 394 behavior. In the same way, the presence of EWGs in the hydrophilic compounds IBP ($395 \mathrm{COOH}), \mathrm{DCF}(-\mathrm{COOH} ;-\mathrm{Cl}), \mathrm{CTL}(-\mathrm{F},-\mathrm{C} \equiv \mathrm{N})$ and DZP $(-\mathrm{Cl})$, and in the hydrophobic 396 compounds TCS $(-\mathrm{Cl})$ and FLX $\left(-\mathrm{CF}_{3},-\mathrm{COR}\right)$ may be a key factor for its low

397 biotransformation (Fig. 4). On the other hand, the complete (or almost complete)

398 biotransformation of SMX in the hydrolytic/acidogenic reactor and in different 399 anaerobic systems (Fig. 4, Table S8a) could be attributed to the presence of EDGs in its 400 molecular structure $\left(-\mathrm{NH}_{2},-\mathrm{CH}_{3},-\mathrm{NHR}\right)$. Likewise, the presence of a hydroxyl bond 
401 (EDG) seems to favor the anaerobic biotransformation of the hydrophobic surfactants

402 OP and NP. In contrast, the presence of this EDG in the E1, E2, and EE2 molecules did 403 not lead to relevant biotransformation efficiencies (Fig. 4).

404 Although the presence of EDGs and EWGs is an important factor in the OMP 405 biotransformation, it may be also influenced by other features related to the 406 bioavailability and physicochemical characteristics of the compounds such as 407 hydrophobicity, partition coefficient and molecular weight [14,35,77]. For instance, the 408 compounds with higher sorption capacity $\left(\log \mathrm{K}_{\mathrm{D}}>2.5\right)$ and with EDGs in their 409 molecular structure - AHTN, HHCB, ADBI, OP, NP, showed a medium 410 biotransformation efficiency (50 - 80\%), suggesting that biotransformation might occur 411 after sorption onto the biomass. Indeed, compounds with EDGs but with lower sorption 412 capacity $\left(\log \mathrm{K}_{\mathrm{D}}<2.5-\mathrm{E} 1 / \mathrm{E} 2\right.$, EE2, and BPA) were poorly biotransformed (Fig. 4).

413 In order to evaluate the relevance of hydrolysis/acidogenesis on the biotransformation

414 of the OMPs during anaerobic processes, our $k_{b i o l}$ values were compared with those

415 previously obtained by Alvarino et al. [19] in a pilot-scale UASB reactor. Despite most 416 compounds presenting similar $k_{\text {biol }}$ values in both systems (Table S7), some OMPs 417 changed their biotransformation category: TMP and NPX with a moderate and low 418 biotransformation during hydrolysis/acidogenesis presented a higher rate in the UASB 419 reactor, while the $k_{b i o l}$ of HHCB, AHTN, ROX, and ERY was medium in the 420 hydrolytic/acidogenic reactor and low in the UASB reactor. Unfortunately, few 421 anaerobic $k_{\text {biol }}$ data are available in the literature, and thus a broader comparison is 422 established in Fig. 4 with the removal efficiencies reported for a variety of anaerobic 423 systems at bench, pilot and full scale (i.e., batch experiments, sludge digesters, UASB 424 reactors, and anaerobic membrane bioreactors). The details about the removal 425 efficiencies and the operational parameters of each study are provided in Tables 
S7a/S7b. As can be inferred from Table S8 and according to many authors

$427[6,18,28,33,34,78]$, no clear correlations were found between operating conditions and

428 OMP biotransformation, which is why data obtained in different anaerobic

429 technological applications were used to compare our $k_{\text {biol }}$ values (Table S7) and

430 biotransformation efficiencies (Fig. 4). It should be noted that the comparison of Fig. 4

431 is qualitative, since most references do not separate the total removal (biotransformation

432 + sorption) from what is actually biotransformed. In addition, for some compounds, the

433 reported results either show a large deviation or are scarce $(\mathrm{n} \leq 5$ for ADBI, AHTN, OP,

434 ERY, and CTL). Nonetheless, it could be inferred from Fig. 4 that the anaerobic

435 biotransformation of most OMPs might cometabolically occur during the

436 hydrolysis/acidogenesis of carbohydrates; even for some compounds (i.e., HHCB,

437 ADBI, and ERY) it appears to be favored during this anaerobic stage, as previously

438 observed with $k_{b i o l}$ data. Only for some OMPs (i.e., TMP, NPX, and CTL), the

439 hydrolytic/acidogenic step seems to play a minor role in their anaerobic removal, thus

440 other anaerobic stages as acetogenesis, methanogenesis or even hydrolysis/acidogenesis

441 of other substrates (e.g., proteins and lipids) might be responsible for their

442 biotransformation.

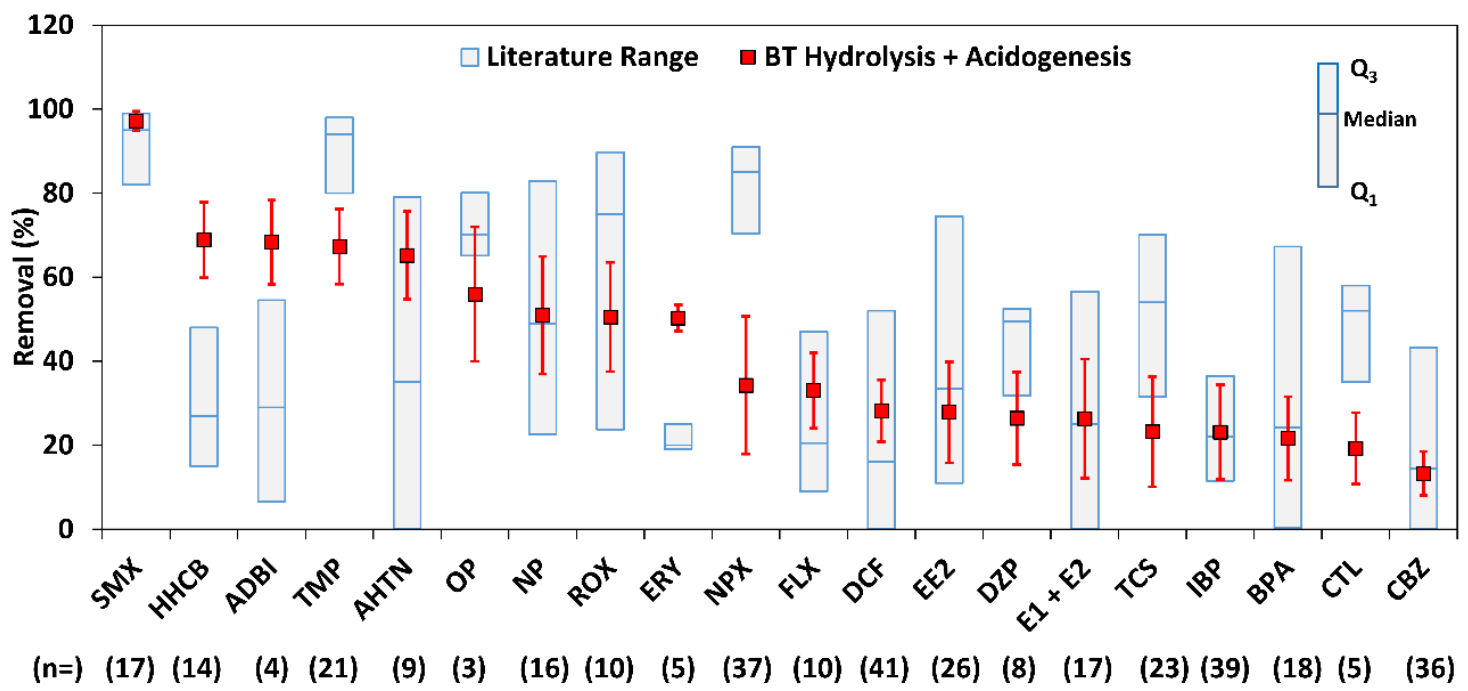

Fig. 4. Comparison between the OMPs biotransformation (BT) in the 
445 hydrolytic/acidogenic step $(\mathrm{n}=15)$ and the reported removal values of the overall

446 anaerobic digestion process. The literature data range is detailed in Table S8a. The

447 number of reported values is shown in brackets $(n=)$. Since E1 is converted naturally

448 into E2 under anaerobic conditions [79], the results in terms of biotransformation are

449 computed together $(\mathrm{E} 1+\mathrm{E} 2)$.

450

\subsection{Anaerobic stages involved in the biotransformation of OMPs}

\subsubsection{Hydrolysis versus acidogenesis}

453 Starch and glucose fermentation are similar processes since starch consists of a large number of glucose units joined by glycosidic bonds, and therefore they only differ in the first step, starch hydrolysis to glucose, which is mainly conducted by glycosidase enzymes (Fig. S5 - enzymatic pathway of starch hydrolysis to glucose). Then, acidogenic enzymes degrade glucose into VFA and other soluble fermentation products.

458 The acidogenic fermentation of glucose represents a key step during anaerobic degradation of the wide variety of industrial wastes, as well as sewage and sludge from wastewater treatment plants $[46,68,80,81]$.

461 We hypothesized that the higher activity of hydrolases (i.e., glycosidases) during starch

462 fermentation might have resulted in a greater cometabolic biotransformation of certain

463 OMPs (e.g., ERY and ROX that have a glycosidic bond). However, our experimental 464 results do not support this theory. As shown in Fig. 5, all OMPs were biotransformed to 465 the same extent in both operational periods: starch (hydrolysis + acidogenesis) and 466 glucose (acidogenesis) fermentation. Actually, the results were statistically equal 467 (ANOVA with a 5\% significance level) and the differences between both 468 biotransformation efficiencies did not exceed 10 percentage points for any OMP. These 469 results suggest that hydrolysis of carbohydrates plays a minor role in the anaerobic 
470 biotransformation of OMPs, while acidogenesis should be considered as a key step. It

471 cannot be ruled out that, apart from glycosidases, other hydrolases might be present

472 during starch and even glucose fermentation. However, their activity and cometabolic

473 action towards the OMPs may be low in comparison with the enzymes involved in the

474 metabolism of the main carbon source (starch or glucose).

475 Finally, it should be noted that the differences found in the performance of both

476 operational periods (starch and glucose fermentation), particularly butyric acid

477 conversion (see Section 3.1) did not affect the biotransformation of OMPs. Thus, either

478 these differences did not alter the metabolic pathways for glucose acidification or the

479 different pathways presented common enzymatic activities responsible for the

480 biotransformation of OMPs.

481

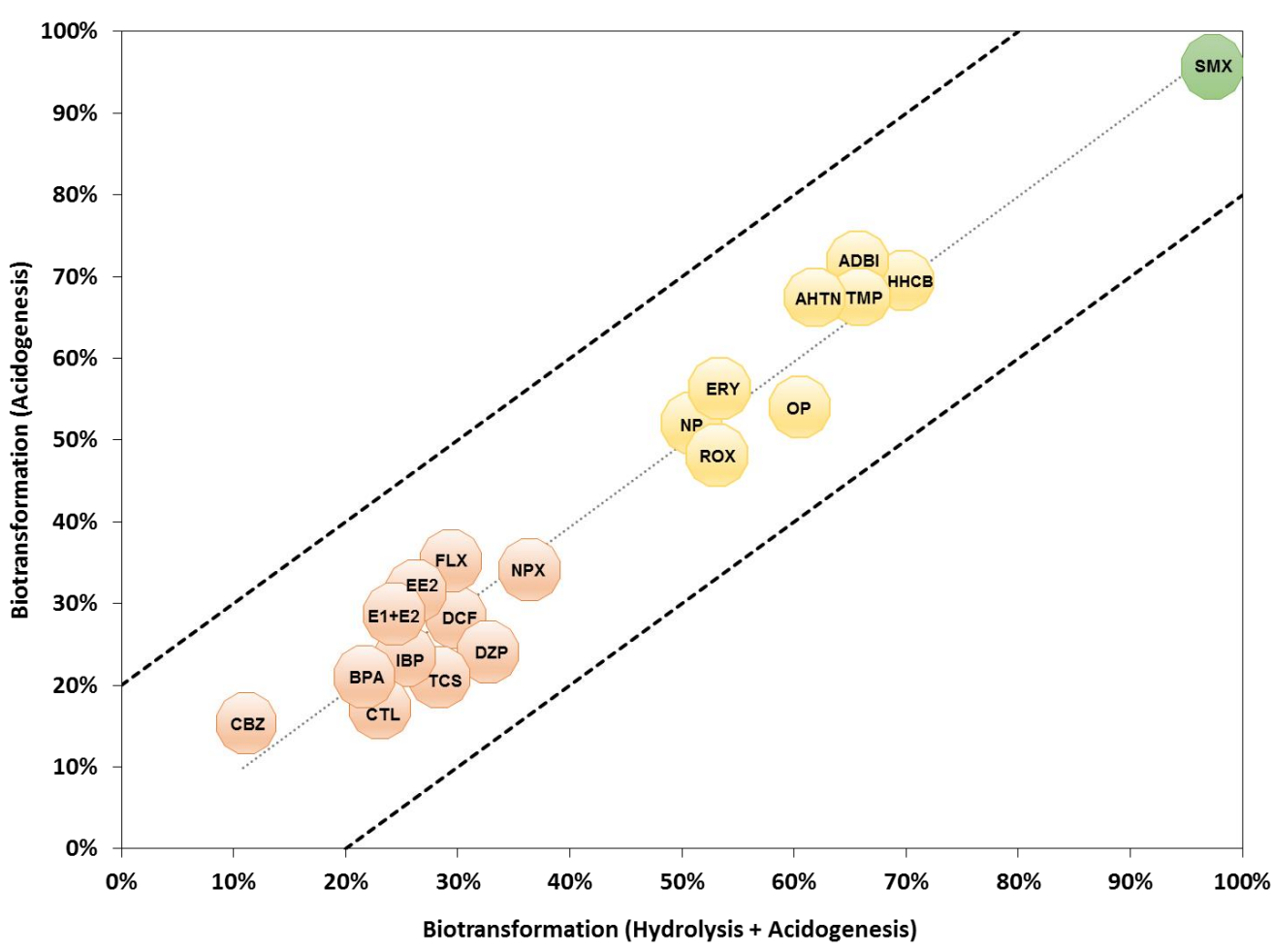

482 
483 Fig. 5. Correlation between the OMPs biotransformation in hydrolysis + acidogenesis

484 (starch fermentation, $\mathrm{n}=6$ ) and only the acidogenic step (glucose fermentation, $\mathrm{n}=9$ ).

485 The detailed values are summarized in Table S5.

486

\subsubsection{Acidogenesis versus methanogenesis}

In Fig. 6, the biotransformation efficiencies attained in the fermentation reactor are compared with those obtained by Gonzalez-Gil et al. [36] in a methanogenic reactor fed with a mixture of VFA and enriched in heteroacetogens and aceticlastic methanogens.

491 Overall, it can be concluded that acidogenesis and acetogenesis/methanogenesis are involved in the anaerobic biotransformation of the studied OMPs. However, the relative contribution of each stage differs among compounds, which can be divided into three groups (Fig. 6): (a) OMPs with a biotransformation significantly $(\mathrm{p} \leq 0.05)$ higher in acidogenic conditions (HHCB, ADBI, AHTN, ERY, and ROX); (b) compounds equally biotransformed in both stages ( $\mathrm{p}>0.05)$; and $(c)$ OMPs whose biotransformation is significantly $(\mathrm{p} \leq 0.05)$ favored in acetogenic/methanogenic conditions (FLX, CBZ, BPA, and TCS).

As shown in Fig. 6, no significant differences $(\mathrm{p}>0.05)$ between the biotransformation efficiencies during acidogenesis and acetogenesis/methanogenesis were observed for most OMPs (group $b$ ), indicating that both microbial populations have the same

502 capacity to transform them despite having very different metabolic pathways. Indeed, SMX, which is completely biotransformed in acidogenesis and acetogenesis/methanogenesis, possibly undergoes a cleavage of its isoxazole ring under iron-reducing conditions [82]. This reaction might be indirectly mediated by the action

506 of cytochrome c or membrane-bound hydrogenases [83], involved in several biological

507 pathways like aceticlastic methanogenesis and glucose catabolism [84]. Yet, for most 
508 OMPs, it remains unknown if they follow the same or different biotransformation

509 pathways (catalyzed by common or specific enzymatic activities of each stage). In

510 agreement with our results, Braun et al. [85] did not find significant differences between

511 the removal of polycyclic aromatic hydrocarbons in anaerobic reactors with

512 fermentative, methanogenic and intermediate activities, suggesting that

513 biotransformation of these compounds does not depend on the main metabolic activities

514 or the dominant microbial communities of the reactor.

515 On the other hand, OMPs from groups $(a)$ and $(c)$ presented differences in the

516 biotransformation capacity of both stages, which indicates that the stimulation of

517 specific enzymatic activities in the fermentation or methanogenic reactors may have

518 contributed to the greater biotransformation. For instance, in the case of the macrolides

519 ERY and ROX, the higher biotransformation in acidogenesis could be due to the higher

520 activity of glycosylase enzymes, which could cleave their hexose sugar (cladinose).

521 Actually, this hypothesis is supported by experiments recently performed with

522 anaerobic sludge enzymes [83]. Regarding ADBI and AHTN, the dominance of

523 fermentative species during acidogenesis might have favored some enzymatic

524 mechanisms related to the biotransformation of these compounds, as it could be the case

525 of the enzyme 3-hydroxybutyryl-CoA dehydrogenase that reduces ketone groups to

526 convert acetoacetyl-CoA to 3-hydroxybutyryl-CoA in the butyric acid metabolic route.

527 Certainly, the greater activity of other acidogenic enzymes in the fermentation reactor

528 might also explain why compounds from the group $(a)$ achieved a higher

529 biotransformation respect to the overall anaerobic digestion process (Fig. 4). On the

530 contrary, the biotransformation of BPA and TCS (group (c), Fig. 6) was favored during

531 acetogenesis/methanogenesis, which could be due to an increase in the activity of 
532 acetate kinase, a methanogenic enzyme able to phosphorylate their hydroxyl groups $533[17,86]$.

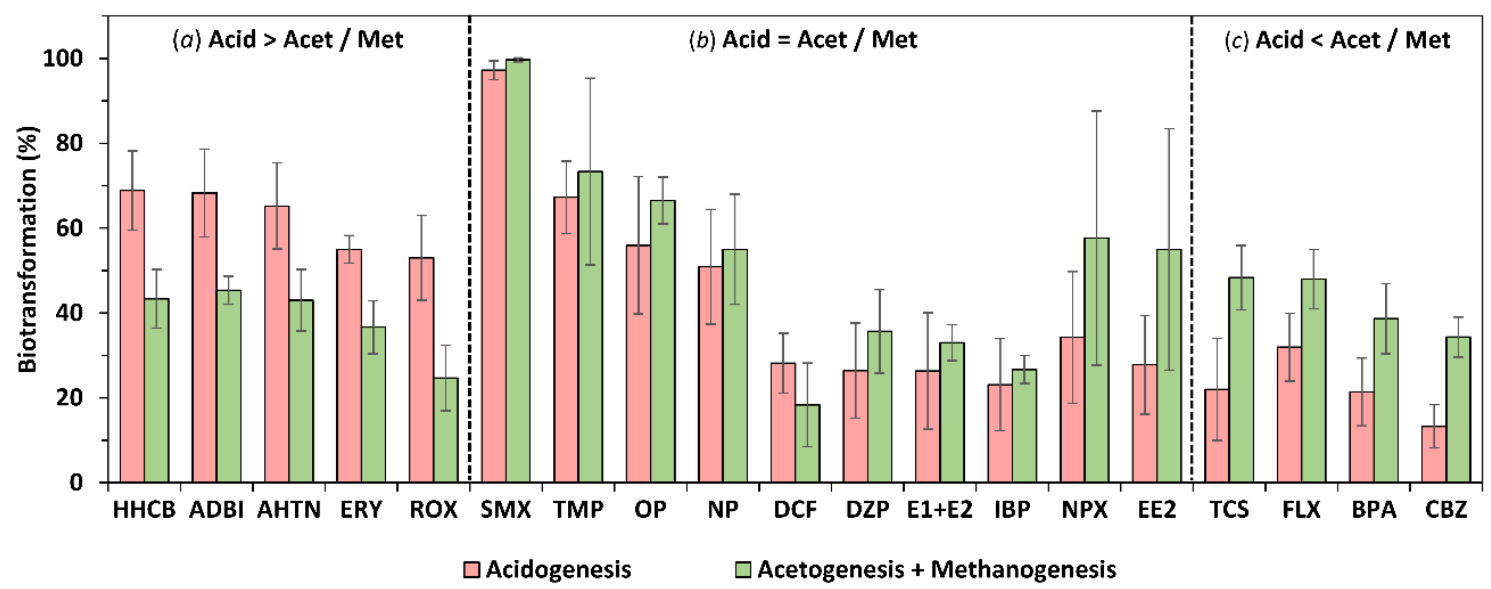

535 Fig. 6. Comparison between the biotransformation of OMPs during acidogenesis $(n=15$,

536 fermentation reactor) and acetogenesis/methanogenesis ( $\mathrm{n}=3$, methanogenic reactor

537 [36]). The compounds were divided into 3 groups: (a) Acid > Acet/Met, (c) Acid <

538 Acet/Met (biotransformation differences $\geq 15$ percentage points and $\mathrm{p} \leq 0.05$ ); and Acid

$539=$ Acet/Met (biotransformation differences $<15$ percentage points and/or $\mathrm{p}>0.05$ ).

541 Finally, as previously pointed out in Fig. 4, the anaerobic biotransformation of some

542 compounds (i.e., TMP and NPX) does not completely occur during acidogenesis, thus

543 other anaerobic steps should be involved. However, according to the results of

544 Gonzalez-Gil et al. [36] for TMP and NPX (Fig. 6), these differences can neither be

545 explained by heteroacetogenesis and aceticlastic methanogenesis. Wolfson et al. [87]

546 have recently found that NPX is possibly O-demethylated through a consortium of

547 homoacetogens, acetate oxidizers, and hydrogenotrophic methanogens with a

548 syntrophic relationship. Actually, the demethylation of the methoxy groups of NPX and

549 TMP is quite common in anaerobic processes [15]. However, the activities of this

550 microbial consortium were not promoted in the acidogenic and methanogenic reactors, 
551 which could explain the higher biotransformation efficiencies ( $\geq 95 \%)$ achieved in the

552 overall anaerobic digestion (Fig. 4) for NPX and TMP in comparison with the results

553 attained in the acidogenic and methanogenic reactors (Fig. 6).

554

555

\section{CONCLUSIONS}

556 The main conclusion of this study is that the acidogenic phase of the anaerobic

557 digestion processes is key in the biotransformation of OMPs, while the hydrolysis of

558 carbohydrates does not significantly contribute to the cometabolic transformation of the

559 studied compounds. The biotransformation of HHCB, ADBI, AHTN, ERY and ROX

560 was favored under acidogenic conditions compared to acetogenesis/methanogenesis. On

561 the contrary, the biotransformation of other compounds, e.g. TCS, FLX, BPA, and CBZ

562 depends on acetogenesis/methanogenesis. Thus, the separation of the

563 hydrolytic/acidogenic and acetogenic/methanogenic phases in anaerobic treatment

564 technologies can be a promising alternative for enhancing OMPs biotransformation.

565 The molecular structure of OMPs appears to be an important factor in their anaerobic

566 biotransformation. Namely, the presence of EDGs might explain the high

567 biotransformation of some compounds (e.g., SMX and TMP), while EWGs could have

568 a negative effect (e.g., CBZ, IBP, DCF, FLX, TCS, DZP, and CTL). However, to

569 explain the differences found between the biotransformation during acidogenesis,

570 methanogenesis and the overall anaerobic digestion process, other aspects, such as the

571 specific enzymatic activities promoted should be considered.

573 Disclosure statement

574 There is no conflict of interest by the authors. 
576 Acknowledgments

577 This work was funded by São Paulo Research Foundation (FAPESP), process $\mathrm{n}^{\circ}$

578 2017/13066-0 and the Spanish Government (AEI) through COMETT Project

579 (CTQ2016-80847-R). Authors from Universidade de Santiago de Compostela belong to

580 CRETUS Strategic Partnership (ED431E 2018/01) and to Galicia Competitive Research

581 Group (GRC ED431C 2017/29), programs co-funded by FEDER (EU). We would like

582 to thank Alberte Regueira for his valuable support with mass balances.

583 


\section{REFERENCES}

585

586

587

588

589

590

591

592

593

594

595

596

597

598

599

600

601

602

603

604

605

606

607

608

609

610

611

612

613

614

615

616

617

618

619

620

621

622

623

624

625

626

627

[1] G.U. Semblante, F.I. Hai, X. Huang, A.S. Ball, W.E. Price, L.D. Nghiem, Trace organic contaminants in biosolids: Impact of conventional wastewater and sludge processing technologies and emerging alternatives, J. Hazard. Mater. 300 (2015) 1-17. https://doi.org/10.1016/j.jhazmat.2015.06.037.

[2] M. Carballa, F. Omil, J.M. Lema, M. Llompart, C. García-Jares, I. Rodríguez, M. Gómez, T. Ternes, Behavior of pharmaceuticals, cosmetics and hormones in a sewage treatment plant, Water Res. 38 (2004) 2918-2926. https://doi.org/10.1016/j.watres.2004.03.029.

[3] T.A. Ternes, M. Bonerz, N. Herrmann, B. Teiser, H.R. Andersen, Irrigation of treated wastewater in Braunschweig, Germany: An option to remove pharmaceuticals and musk fragrances, Chemosphere. 66 (2007) 894-904. https://doi.org/10.1016/j.chemosphere.2006.06.035.

[4] R.B. Carneiro, C.A. Sabatini, Á.J. Santos-Neto, M. Zaiat, Feasibility of anaerobic packed and structured-bed reactors for sulfamethoxazole and ciprofloxacin removal from domestic sewage, Sci. Total Environ. 678 (2019) 419-429. https://doi.org/10.1016/j.scitotenv.2019.04.437.

[5] N.H. Tran, M. Reinhard, K.Y.H. Gin, Occurrence and fate of emerging contaminants in municipal wastewater treatment plants from different geographical regions-a review, Water Res. 133 (2018) 182-207. https://doi.org/10.1016/j.watres.2017.12.029.

[6] L. Gonzalez-Gil, M. Papa, D. Feretti, E. Ceretti, G. Mazzoleni, N. Steimberg, R. Pedrazzani, G. Bertanza, J.M. Lema, M. Carballa, Is anaerobic digestion effective for the removal of organic micropollutants and biological activities from sewage sludge?, Water Res. 102 (2016) 211-220. https://doi.org/10.1016/j.watres.2016.06.025.

[7] H.Q. Liu, J.C.W. Lam, W.W. Li, H.Q. Yu, P.K.S. Lam, Spatial distribution and removal performance of pharmaceuticals in municipal wastewater treatment plants in China, Sci. Total Environ. 586 (2017) 1162-1169. https://doi.org/10.1016/j.scitotenv.2017.02.107.

[8] B. Li, T. Zhang, Biodegradation and adsorption of antibiotics in the activated sludge process, Environ. Sci. Technol. 44 (2010) 3468-3473. https://doi.org/10.1021/es903490h.

[9] M. Carballa, F. Omil, J.M. Lema, Removal of cosmetic ingredients and pharmaceuticals in sewage primary treatment, Water Res. 39 (2005) 4790-4796. https://doi.org/10.1016/j.watres.2005.09.018.

[10] A.S. Stasinakis, Review on the fate of emerging contaminants during sludge anaerobic digestion, Bioresour. Technol. 121 (2012) 432-440. https://doi.org/10.1016/j.biortech.2012.06.074.

[11] J. Peng, X. Wang, F. Yin, G. Xu, Characterizing the removal routes of seven pharmaceuticals in the activated sludge process, Sci. Total Environ. 650 (2019) 2437-2445. https://doi.org/10.1016/j.scitotenv.2018.10.004.

[12] K. Fischer, M. Majewsky, Cometabolic degradation of organic wastewater micropollutants by activated sludge and sludge-inherent microorganisms, Appl. 
Microbiol. Biotechnol. 98 (2014) 6583-6597. https://doi.org/10.1007/s00253014-5826-0.

[13] A. Arias, T. Alvarino, T. Allegue, S. Suárez, J.M. Garrido, F. Omil, An innovative wastewater treatment technology based on UASB and IFAS for cost-

[14] K.C. Wijekoon, J.A. McDonald, S.J. Khan, F.I. Hai, W.E. Price, L.D. Nghiem, Development of a predictive framework to assess the removal of trace organic chemicals by anaerobic membrane bioreactor, Bioresour. Technol. 189 (2015) 391-398. https://doi.org/10.1016/j.biortech.2015.04.034.

[15] A.K. Ghattas, F. Fischer, A. Wick, T.A. Ternes, Anaerobic biodegradation of (emerging) organic contaminants in the aquatic environment, Water Res. 116 (2017) 268-295. https://doi.org/10.1016/j.watres.2017.02.001.

[16] H. V. Phan, R. Wickham, S. Xie, J.A. McDonald, S.J. Khan, H.H. Ngo, W. Guo, L.D. Nghiem, The fate of trace organic contaminants during anaerobic digestion of primary sludge: A pilot scale study, Bioresour. Technol. 256 (2018) 384-390. https://doi.org/10.1016/j.biortech.2018.02.040.

[17] L. Gonzalez-Gil, M. Carballa, J.M. Lema, Cometabolic Enzymatic Transformation of Organic Micropollutants under Methanogenic Conditions, Environ. Sci. Technol. 51 (2017) 2963-2971. https://doi.org/10.1021/acs.est.6b05549.

[18] S. Yang, F.I. Hai, W.E. Price, J. McDonald, S.J. Khan, L.D. Nghiem, Occurrence of trace organic contaminants in wastewater sludge and their removals by anaerobic digestion, Bioresour. Technol. 210 (2016) 153-159. https://doi.org/10.1016/j.biortech.2015.12.080.

[19] T. Alvarino, S. Suárez, M. Garrido, J.M. Lema, F. Omil, A UASB reactor coupled to a hybrid aerobic MBR as innovative plant configuration to enhance the removal of organic micropollutants, Chemosphere. 144 (2016) 452-458. https://doi.org/10.1016/j.chemosphere.2015.09.016.

[20] T. Alvarino, S. Suarez, J.M. Lema, F. Omil, Understanding the removal mechanisms of PPCPs and the influence of main technological parameters in anaerobic UASB and aerobic CAS reactors, J. Hazard. Mater. 278 (2014) 506513. https://doi.org/10.1016/j.jhazmat.2014.06.031.

[21] M. Narumiya, N. Nakada, N. Yamashita, H. Tanaka, Phase distribution and removal of pharmaceuticals and personal care products during anaerobic sludge digestion, J. Hazard. Mater. 260 (2013) 305-312. https://doi.org/10.1016/j.jhazmat.2013.05.032.

[22] S. Yang, J. McDonald, F.I. Hai, W.E. Price, S.J. Khan, L.D. Nghiem, Effects of thermal pre-treatment and recuperative thickening on the fate of trace organic contaminants during anaerobic digestion of sewage sludge, Int. Biodeterior. Biodegrad. 124 (2017) 146-154. https://doi.org/10.1016/j.ibiod.2017.06.002.

[23] C.A.L. Chernicharo, J.B. van Lier, A. Noyola, T. Bressani Ribeiro, Anaerobic sewage treatment: state of the art, constraints and challenges, Rev. Environ. Sci. Biotechnol. 14 (2015) 649-679. https://doi.org/10.1007/s11157-015-9377-3.

[24] L. Feng, Y. Chen, X. Zheng, Enhancement of waste activated sludge protein 
682

683

684

685

686

687

688

689

690

691

692

693

694

695

696

697

698

699

700

701

702

703

704

705

706

707

708

709

710

711

712

713

714

715

716

717

conversion and volatile fatty acids accumulation during waste activated sludge anaerobic fermentation by carbohydrate substrate addition: The effect of $\mathrm{pH}$, Environ. Sci. Technol. 43 (2009) 4373-4380. https://doi.org/10.1021/es8037142.

[25] C.M. Bethke, R.A. Sanford, M.F. Kirk, Q. Jin, T.M. Flynn, The thermodynamic ladder in geomicrobiology, Am. J. Sci. 311 (2011) 183-210. https://doi.org/10.2475/03.2011.01.

[26] C. Zhang, G.N. Bennett, Biodegradation of xenobiotics by anaerobic bacteria, Appl. Microbiol. Biotechnol. 67 (2005) 600-618. https://doi.org/10.1007/s00253004-1864-3.

[27] M. Carballa, F. Omil, A.C. Alder, J.M. Lema, Comparison between the conventional anaerobic digestion of sewage sludge and its combination with a chemical or thermal pre-treatment concerning the removal of pharmaceuticals and personal care products, Water Sci. Technol. 53 (2006) 109-117. https://doi.org/10.2166/wst.2006.241.

[28] V.G. Samaras, A.S. Stasinakis, N.S. Thomaidis, D. Mamais, T.D. Lekkas, Bioresource Technology Fate of selected emerging micropollutants during mesophilic , thermophilic and temperature co-phased anaerobic digestion of sewage sludge, Bioresour. Technol. 162 (2014) 365-372. https://doi.org/10.1016/j.biortech.2014.03.154.

[29] V.G. Samaras, A.S. Stasinakis, D. Mamais, N.S. Thomaidis, T.D. Lekkas, Fate of selected pharmaceuticals and synthetic endocrine disrupting compounds during wastewater treatment and sludge anaerobic digestion, J. Hazard. Mater. 244-245 (2013) 259-267. https://doi.org/10.1016/j.jhazmat.2012.11.039.

[30] X. Song, W. Luo, J. McDonald, S.J. Khan, F.I. Hai, W.E. Price, L.D. Nghiem, An anaerobic membrane bioreactor - membrane distillation hybrid system for energy recovery and water reuse: Removal performance of organic carbon, nutrients, and trace organic contaminants, Sci. Total Environ. 628-629 (2018) 358-365. https://doi.org/10.1016/j.scitotenv.2018.02.057.

[31] T. Alvarino, S. Suárez, M. Garrido, J.M. Lema, F. Omil, A UASB reactor coupled to a hybrid aerobic MBR as innovative plant configuration to enhance the removal of organic micropollutants, Chemosphere. 144 (2015) 452-458. https://doi.org/10.1016/j.chemosphere.2015.09.016.

[32] M. Narumiya, N. Nakada, N. Yamashita, H. Tanaka, Phase distribution and removal of pharmaceuticals and personal care products during anaerobic sludge digestion, J. Hazard. Mater. 260 (2013) 305-312. https://doi.org/10.1016/j.jhazmat.2013.05.032.

[33] M. Carballa, F. Omil, T. Ternes, J.M. Lema, Fate of pharmaceutical and personal care products (PPCPs) during anaerobic digestion of sewage sludge, Water Res. 41 (2007) 2139-2150. https://doi.org/10.1016/j.watres.2007.02.012.

[34] J. Malmborg, J. Magnér, Pharmaceutical residues in sewage sludge: Effect of sanitization and anaerobic digestion, J. Environ. Manage. 153 (2015) 1-10. https://doi.org/10.1016/j.jenvman.2015.01.041.

[35] V.M. Monsalvo, J.A. McDonald, S.J. Khan, P. Le-Clech, Removal of trace organics by anaerobic membrane bioreactors, Water Res. 49 (2014) 103-112. https://doi.org/10.1016/j.watres.2013.11.026. 
[36] L. Gonzalez-Gil, M. Mauricio-Iglesias, D. Serrano, J.M. Lema, M. Carballa, Role of methanogenesis on the biotransformation of organic micropollutants during anaerobic digestion, Sci. Total Environ. 622-623 (2018) 459-466. https://doi.org/10.1016/j.scitotenv.2017.12.004.

[37] J.L. García-Morales, E. Nebot, L.I. Romero, D. Sales, Comparison Between Acidogenic and Methanogenic Inhibition Caused by Linear AlkylbenzeneSulfonate ( LAS ), Chem. Biochem. Eng. Q. 15 (2001) 13-19.

[38] R.U. Meckenstock, M. Boll, H. Mouttaki, J.S. Koelschbach, P. Cunha Tarouco, P. Weyrauch, X. Dong, A.M. Himmelberg, Anaerobic degradation of benzene and polycyclic aromatic hydrocarbons, J. Mol. Microbiol. Biotechnol. 26 (2016) 92-118. https://doi.org/10.1159/000441358.

[39] M. Carmona, M.T. Zamarro, B. Blazquez, G. Durante-Rodriguez, J.F. Juarez, J.A. Valderrama, M.J.L. Barragan, J.L. Garcia, E. Diaz, Anaerobic Catabolism of Aromatic Compounds: a Genetic and Genomic View, Microbiol. Mol. Biol. Rev. 73 (2009) 71-133. https://doi.org/10.1128/MMBR.00021-08.

[40] T.B. Hammill, R.L. Crawford, Degradation of 2-sec-butyl-4,6-dinitrophenol (dinoseb) by Clostridium bifermentans KMR-1, Appl. Environ. Microbiol. 62 (1996) 1842-1846.

[41] X. Duan, X. Wang, L. Dai, L. Feng, Y. Yan, Q. Zhou, Simultaneous enhancement of nonylphenol biodegradation and short-chain fatty acids production in waste activated sludge under acidogenic conditions, Sci. Total Environ. 651 (2019) 24-31. https://doi.org/10.1016/j.scitotenv.2018.09.165.

[42] H.Q. Yu, X.J. Zheng, Z.H. Hu, G.W. Gu, High-rate anaerobic hydrolysis and acidogenesis of sewage sludge in a modified upflow reactor, Water Sci. Technol. 48 (2003) 69-75. https://doi.org/10.2166/wst.2003.0224.

[43] A. Taboada-Santos, M. Carballa, N. Morales, J.R. Vázquez-Padín, R. Gutierrez, J.M. Lema, An optimised control system to steer the transition from anaerobic mono- to co-digestion in full-scale plants, Environ. Sci. Water Res. Technol. 5 (2019) 1004-1011. https://doi.org/10.1039/c9ew00033j.

[44] S.H. Kim, S.K. Han, H.S. Shin, Feasibility of biohydrogen production by anaerobic co-digestion of food waste and sewage sludge, Int. J. Hydrogen Energy. 29 (2004) 1607-1616. https://doi.org/10.1016/j.ijhydene.2004.02.018.

[45] G. Yang, P. Zhang, G. Zhang, Y. Wang, A. Yang, Degradation properties of protein and carbohydrate during sludge anaerobic digestion, Bioresour. Technol. 192 (2015) 126-130. https://doi.org/10.1016/j.biortech.2015.05.076.

[46] M.F. Temudo, R. Kleerebezem, M. VanLoosdrecht, Influence of the pH on (Open) Mixed Culture Fermentation of Glucose: A Chemostat Study, Biotechnol. Bioeng. 98 (2007) 69-79. https://doi.org/10.1002/bit.21412.

[47] A. Regueira, R. González-Cabaleiro, I.D. Ofiţeru, J. Rodríguez, J.M. Lema, Electron bifurcation mechanism and homoacetogenesis explain products yields in mixed culture anaerobic fermentations, Water Res. 141 (2018) 349-356. https://doi.org/10.1016/j.watres.2018.05.013.

[48] C.A. de L. Chernicharo, Anaerobic Reactors, in: Biol. Wastewater Treat. Warm Clim. Reg., IWA Publishing, London, 2015. https://doi.org/10.2166/9781780402116. 
[49] C. Cavinato, C. Da Ros, P. Pavan, D. Bolzonella, Influence of temperature and hydraulic retention on the production of volatile fatty acids during anaerobic fermentation of cow manure and maize silage, Bioresour. Technol. 223 (2017) 59-64. https://doi.org/10.1016/j.biortech.2016.10.041.

[50] I. Angelidaki, W. Sanders, Assessment of the anaerobic biodegradability of macropollutants, Rev. Environ. Sci. Biotechnol. 3 (2004) 117-129. https://doi.org/10.1007/s11157-004-2502-3.

[51] P. Verlicchi, M. Al Aukidy, E. Zambello, Science of the Total Environment Occurrence of pharmaceutical compounds in urban wastewater : Removal, mass load and environmental risk after a secondary treatment - A review, Sci. Total Environ. 429 (2012) 123-155. https://doi.org/10.1016/j.scitotenv.2012.04.028.

[52] M. Clara, O. Gans, G. Windhofer, U. Krenn, W. Hartl, K. Braun, S. Scharf, C. Scheffknecht, Occurrence of polycyclic musks in wastewater and receiving water bodies and fate during wastewater treatment, Chemosphere. 82 (2011) 11161123. https://doi.org/10.1016/j.chemosphere.2010.11.041.

[53] J. Hu, J. Zhao, D. Wang, X. Li, D. Zhang, Q. Xu, L. Peng, Q. Yang, G. Zeng, Effect of diclofenac on the production of volatile fatty acids from anaerobic fermentation of waste activated sludge, Bioresour. Technol. 254 (2018) 7-15. https://doi.org/10.1016/j.biortech.2018.01.059.

[54] Y. Wang, D. Wang, Y. Liu, Q. Wang, F. Chen, Q. Yang, X. Li, G. Zeng, H. Li, Triclocarban enhances short-chain fatty acids production from anaerobic fermentation of waste activated sludge, Water Res. 127 (2017) 150-161. https://doi.org/10.1016/j.watres.2017.09.062.

[55] American Public Health Association (APHA), Standard Methods for the Examination of Water and Wastewater, 21st ed., Washington, DC, USA., American Water Works Association/American Public Works Association/Water Environment Federation, 2005. https://doi.org/10.2105/AJPH.51.6.940-a.

[56] T.A. Ternes, M. Bonerz, N. Herrmann, D. Löffler, E. Keller, B.B. Lacida, A.C. Alder, Determination of pharmaceuticals, iodinated contrast media and musk fragrances in sludge by LC tandem MS and GC/MS, J. Chromatogr. A. 1067 (2005) 213-223. https://doi.org/10.1016/j.chroma.2004.10.096.

[57] J. Garcia-Aguirre, E. Aymerich, J. González-Mtnez. de Goñi, M. EstebanGutiérrez, Selective VFA production potential from organic waste streams: Assessing temperature and pH influence, Bioresour. Technol. 244 (2017) 10811088. https://doi.org/10.1016/j.biortech.2017.07.187.

[58] A. Joss, S. Zabczynski, A. Go, B. Hoffmann, D. Lo, C.S. Mcardell, T.A. Ternes, A. Thomsen, H. Siegrist, Biological degradation of pharmaceuticals in municipal wastewater treatment : Proposing a classification scheme, Water Res. 40 (2006) 1686-1696. https://doi.org/10.1016/j.watres.2006.02.014.

[59] T.A. Ternes, N. Herrmann, M. Bonerz, T. Knacker, H. Siegrist, A. Joss, A rapid method to measure the solid - water distribution coefficient $(\mathrm{Kd})$ for pharmaceuticals and musk fragrances in sewage sludge, Water Res. 38 (2004) 4075-4084. https://doi.org/10.1016/j.watres.2004.07.015.

[60] M. Carballa, G. Fink, F. Omil, J.M. Lema, T. Ternes, Determination of the solidwater distribution coefficient $(\mathrm{Kd})$ for pharmaceuticals, estrogens and musk 
fragrances in digested sludge, Water Res. 42 (2008) 287-295. https://doi.org/10.1016/j.watres.2007.07.012.

[61] Metcalf, Eddy, Wastewater engineering: treatment and reuse, Fourth edition / revised by George Tchobanoglous, Franklin L. Burton, H. David Stensel.

[62] F. Silva, L. Serafim, H. Nadais, L. Arroja, I. Capela, Acidogenic Fermentation Towards Valorisation of Organic Waste Streams into Volatile Fatty Acids, Chem Biochem Eng Q. 27 (2013) 467-476. https://doi.org/10.1016/00220728(95)04447-7.

[63] Ø. Hammer, D. Harper, P. Ryan, Past: Paleontological statistics software package for education and data analysis, Paleontol. Electron. (2001). https://doi.org/10.1016/j.bcp.2008.05.025.

[64] B.E. Logan, S.E. OH, I.S. Kim, S. Van Ginkel, Biological Hydrogen Production Measured in Batch Anaerobic Respirometers, Environ. Sci. Technol. 36 (2002) 2530-2535.

[65] I. Hussy, F.R. Hawkes, R. Dinsdale, D.L. Hawkes, Continuous Fermentative Hydrogen Production from a Wheat Starch Co-Product by Mixed Microflora, Biotechnol. Bioeng. 84 (2003) 619-626. https://doi.org/10.1002/bit.10785.

[66] H. Su, J. Cheng, J. Zhou, W. Song, K. Cen, Improving hydrogen production from cassava starch by combination of dark and photo fermentation, Int. J. Hydrogen Energy. 34 (2009) 1780-1786. https://doi.org/10.1016/j.ijhydene.2008.12.045.

[67] H.H.P. Fang, H. Liu, Effect of $\mathrm{pH}$ on hydrogen production from glucose by a mixed culture, Bioresour. Technol. 82 (2002) 87-93. https://doi.org/10.1016/S0960-8524(01)00110-9.

[68] C.Y. Lin, R.C. Chang, Hydrogen production during the anaerobic acidogenic conversion of glucose, J. Chem. Technol. Biotechnol. 74 (1999) 498-500. https://doi.org/10.1002/(SICI)1097-4660(199906)74:6<498::AIDJCTB67>3.0.CO;2-D.

[69] J.L. Rombouts, G. Mos, D.G. Weissbrodt, R. Kleerebezem, M.C.M. Van Loosdrecht, Diversity and metabolism of xylose and glucose fermenting microbial communities in sequencing batch or continuous culturing, FEMS Microbiol. Ecol. 95 (2019). https://doi.org/10.1093/femsec/fiy233.

[70] A. Göbel, C.S. McArdell, M.J.-F. Suter, W. Giger, Trace Determination of Macrolide and Sulfonamide Antimicrobials, a Human Sulfonamide Metabolite, and Trimethoprim in Wastewater Using Liquid Chromatography Coupled to Electrospray Tandem Mass Spectrometry, Anal. Chem. 76 (2004) 4756-4764. https://doi.org/10.1021/ac0496603.

[71] P.J. Atkins, T.O. Herbert, N.B. Jones, Kinetic studies on the decomposition of erythromycin A in aqueous acidic and neutral buffers, Int. J. Pharm. 30 (1986) 199-207.

[72] J.C. Gasc, S.G. D'Ambrieres, A. Lutz, New ether oxime derivatives a structureactivity of erythromycin a relationship study, J. Antibiot. (Tokyo). 44 (1990) 313-330. https://doi.org/https://doi.org/10.7164/antibiotics.44.313.

[73] T. Mazzei, E. Mini, A. Novelli, P. Periti, Chemistry and mode of action of macrolides, J. Antimicrob. Chemother. 31 (1993) 1-9. 
https://doi.org/10.1093/jac/31.suppl_C.1.

[74] N. Tadkaew, F.I. Hai, J.A. McDonald, S.J. Khan, L.D. Nghiem, Removal of trace organics by MBR treatment: The role of molecular properties, Water Res. 45 (2011) 2439-2451. https://doi.org/10.1016/j.watres.2011.01.023.

[75] J. Tolls, Sorption of veterinary pharmaceuticals in soils: A review, Environ. Sci. Technol. 35 (2001) 3397-3406. https://doi.org/10.1021/es0003021.

[76] J. Stevens-Garmon, J.E. Drewes, S.J. Khan, J.A. McDonald, E.R. V Dickenson, Sorption of emerging trace organic compounds onto wastewater sludge solids, Water Res. 45 (2011) 3417-3426. https://doi.org/10.1016/j.watres.2011.03.056.

[77] Q. Aemig, C. Chéron, N. Delgenès, J. Jimenez, S. Houot, J.P. Steyer, D. Patureau, Distribution of Polycyclic Aromatic Hydrocarbons (PAHs) in sludge organic matter pools as a driving force of their fate during anaerobic digestion, Waste Manag. 48 (2016) 389-396. https://doi.org/10.1016/j.wasman.2015.11.045.

[78] H. Zhou, Z. Zhang, M. Wang, T. Hu, Z. Wang, Enhancement with physicochemical and biological treatments in the removal of pharmaceutically active compounds during sewage sludge anaerobic digestion processes, Chem. Eng. J. (2017). https://doi.org/10.1016/j.cej.2017.01.104.

[79] A. Joss, H. Andersen, T. Ternes, P.R. Richle, H. Siegrist, Removal of estrogens in municipal wastewater treatment under aerobic and anaerobic conditions: Consequences for plant optimization, Environ. Sci. Technol. 38 (2004) 30473055. https://doi.org/10.1021/es0351488.

[80] N. Ren, B. Wang, J.C. Huang, Ethanol-type fermentation from carbohydrate in high rate acidogenic reactor, Biotechnol. Bioeng. 54 (1997) 428-433. https://doi.org/10.1002/(SICI)1097-0290(19970605)54:5<428::AIDBIT3>3.0.CO;2-G.

[81] J.I. Horiuchi, T. Shimizu, K. Tada, T. Kanno, M. Kobayashi, Selective production of organic acids in anaerobic acid reactor by $\mathrm{pH}$ control, Bioresour. Technol. 82 (2002) 209-213. https://doi.org/10.1016/S0960-8524(01)00195-X.

[82] J.L. Mohatt, L. Hu, K.T. Finneran, T.J. Strathmann, Microbially mediated abiotic transformation of the antimicrobial agent sulfamethoxazole under iron-reducing soil conditions, Environ. Sci. Technol. 45 (2011) 4793-4801. https://doi.org/10.1021/es200413g.

[83] L. Gonzalez-Gil, D. Krah, A.-K. Ghattas, M. Carballa, A. Wick, L. Helmholz, J.M. Lema, T.A. Ternes, Biotransformation of organic micropollutants by anaerobic sludge enzymes, Water Res. 152 (2019) 202-214. https://doi.org/10.1016/j.watres.2018.12.064.

[84] J. Ferry, Acetate Metabolism in Anaerobes from the Domain Archaea, Life. 5 (2015) 1454-1471. https://doi.org/10.3390/life5021454.

[85] F. Braun, J. Hamelin, A. Bonnafous, N. Delgenès, J.-P. Steyer, D. Patureau, Similar PAH Fate in Anaerobic Digesters Inoculated with Three Microbial Communities Accumulating Either Volatile Fatty Acids or Methane, PLoS One. 10 (2015) e0125552. https://doi.org/10.1371/journal.pone.0125552.

[86] L. Gonzalez-Gil, M. Carballa, P.F.X. Corvini, J.M. Lema, Reversibility of enzymatic reactions might limit biotransformation of organic micropollutants, 
Sci. Total Environ. 665 (2019) 574-578. https://doi.org/10.1016/j.scitotenv.2019.02.143.

900

[87] S.J. Wolfson, A.W. Porter, J.K. Campbell, L.Y. Young, Naproxen Is

901

902 Transformed Via Acetogenesis and Syntrophic Acetate Oxidation by a

903 Methanogenic Wastewater Consortium, Microb. Ecol. 76 (2018) 362-371. https://doi.org/10.1007/s00248-017-1136-2.

904 


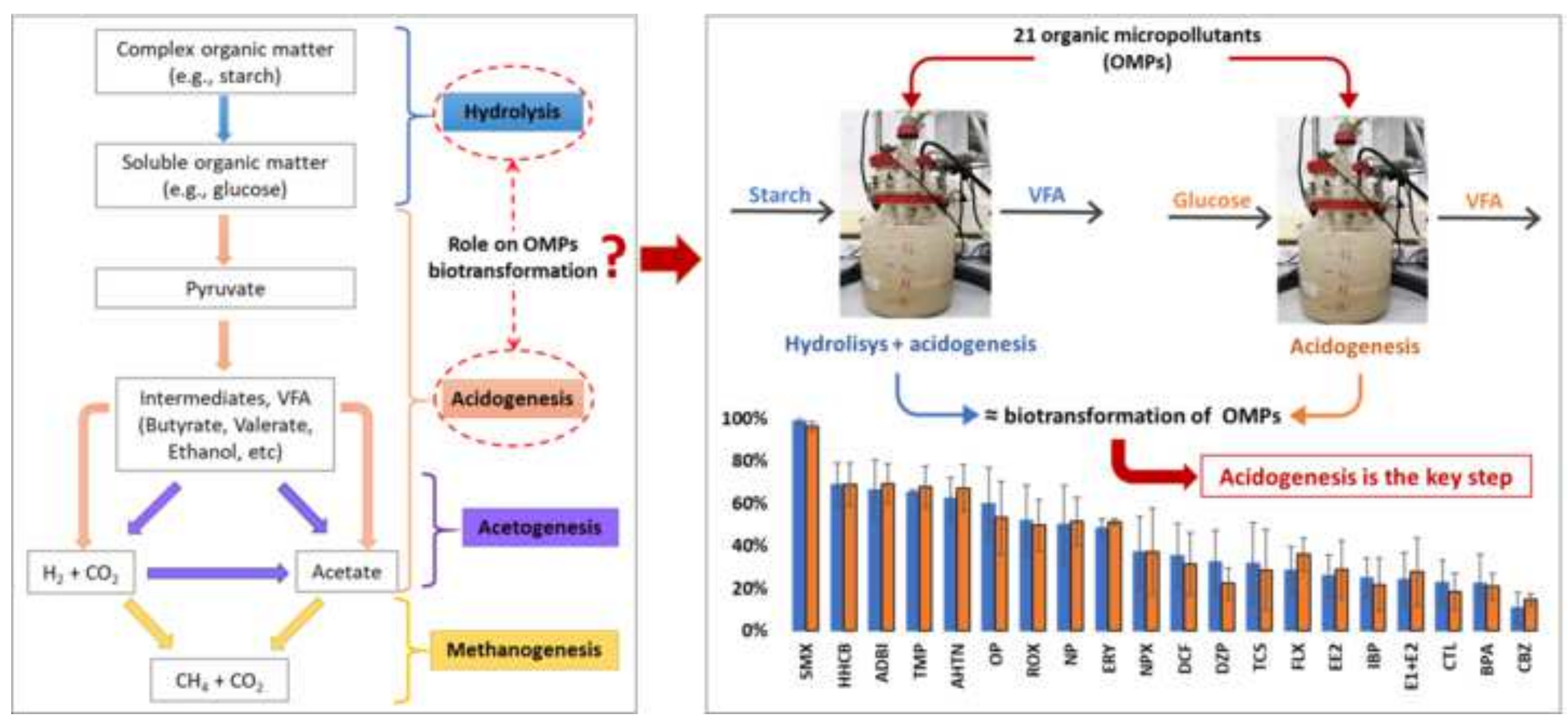




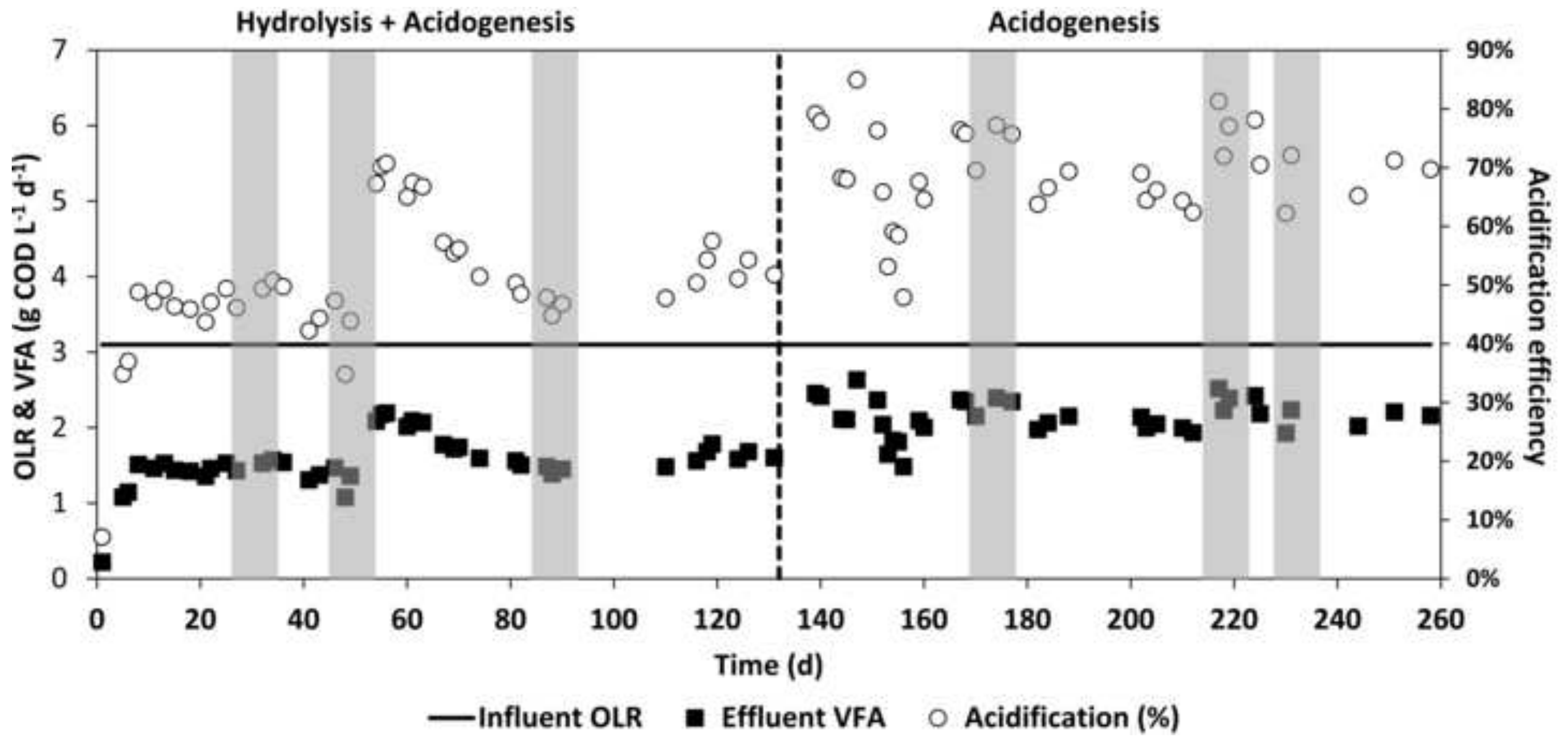




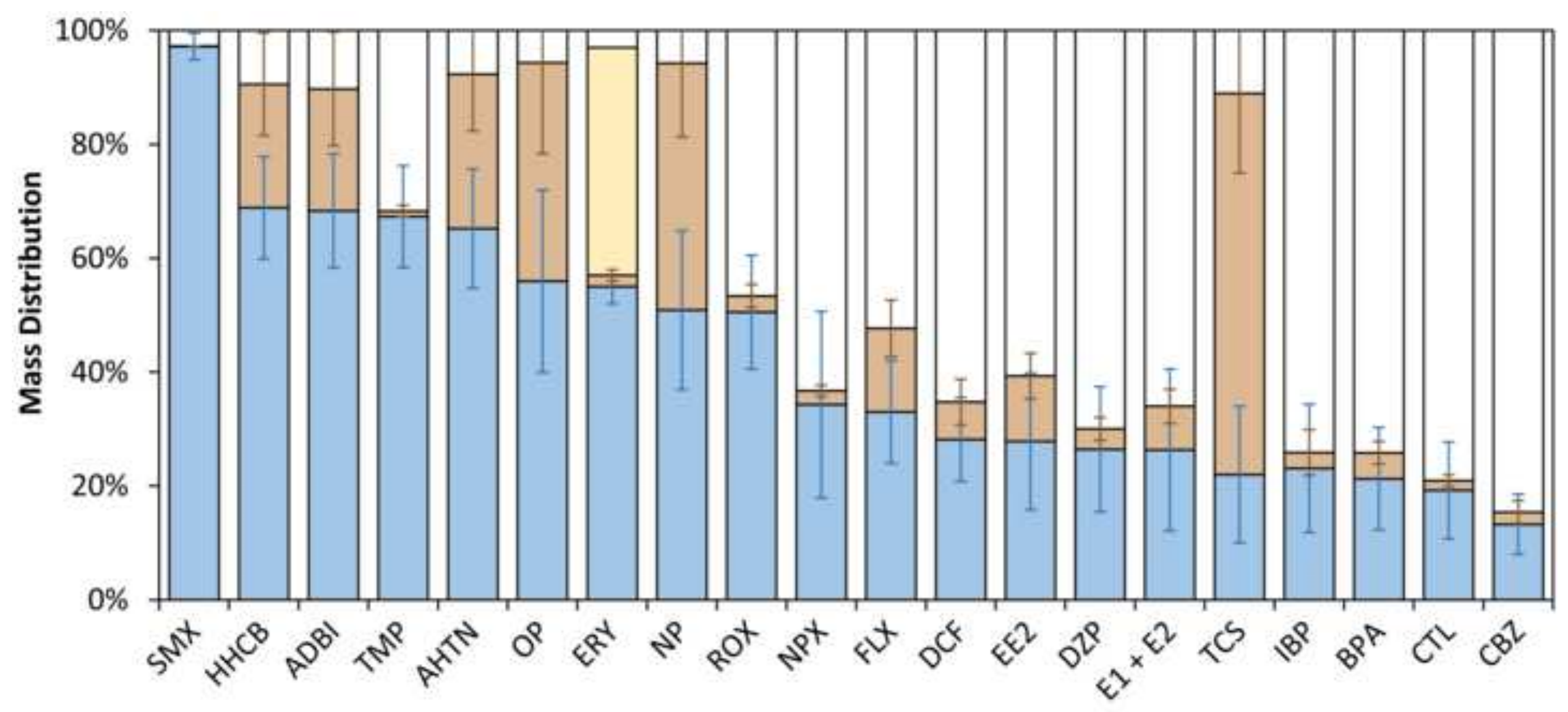

$\square$ Biotransformation $\quad \square$ Sorption $\quad \square$ Abiotic removal $\quad \square$ Remaining in effluent 


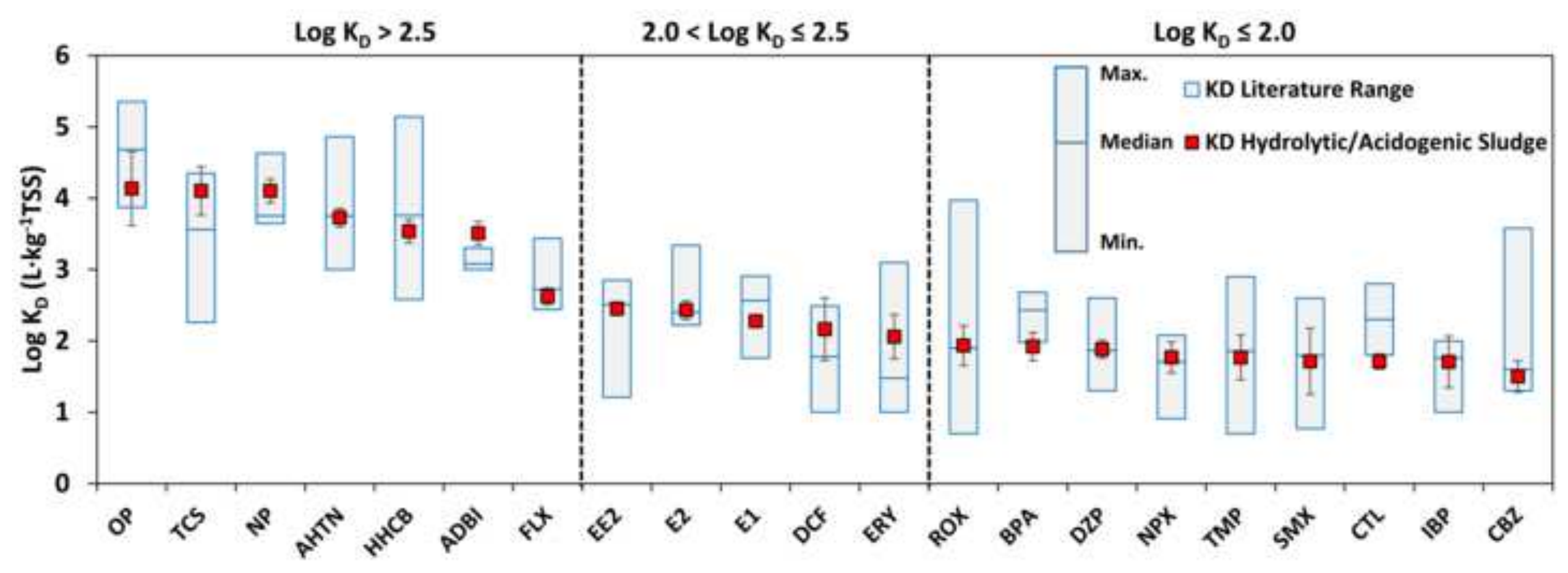




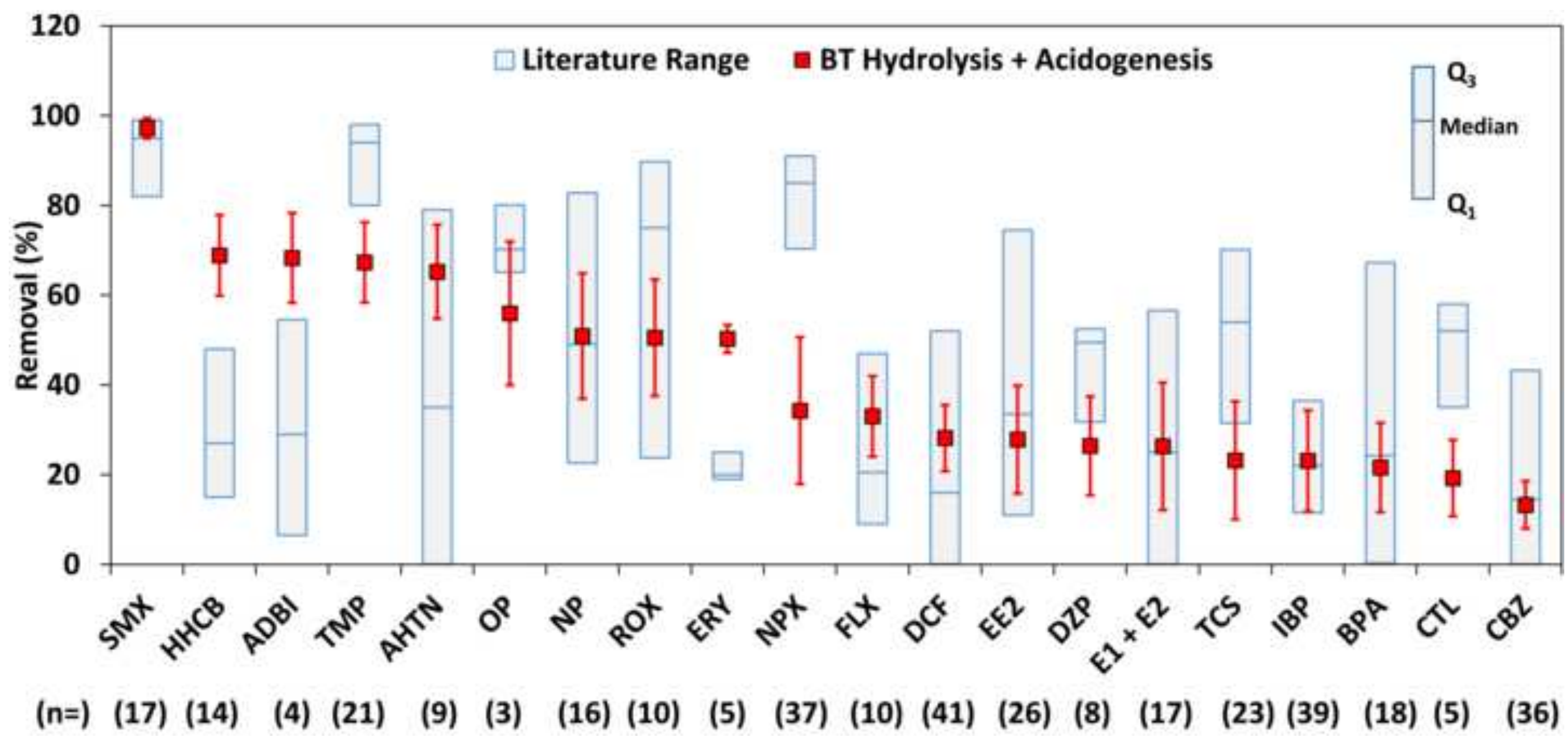




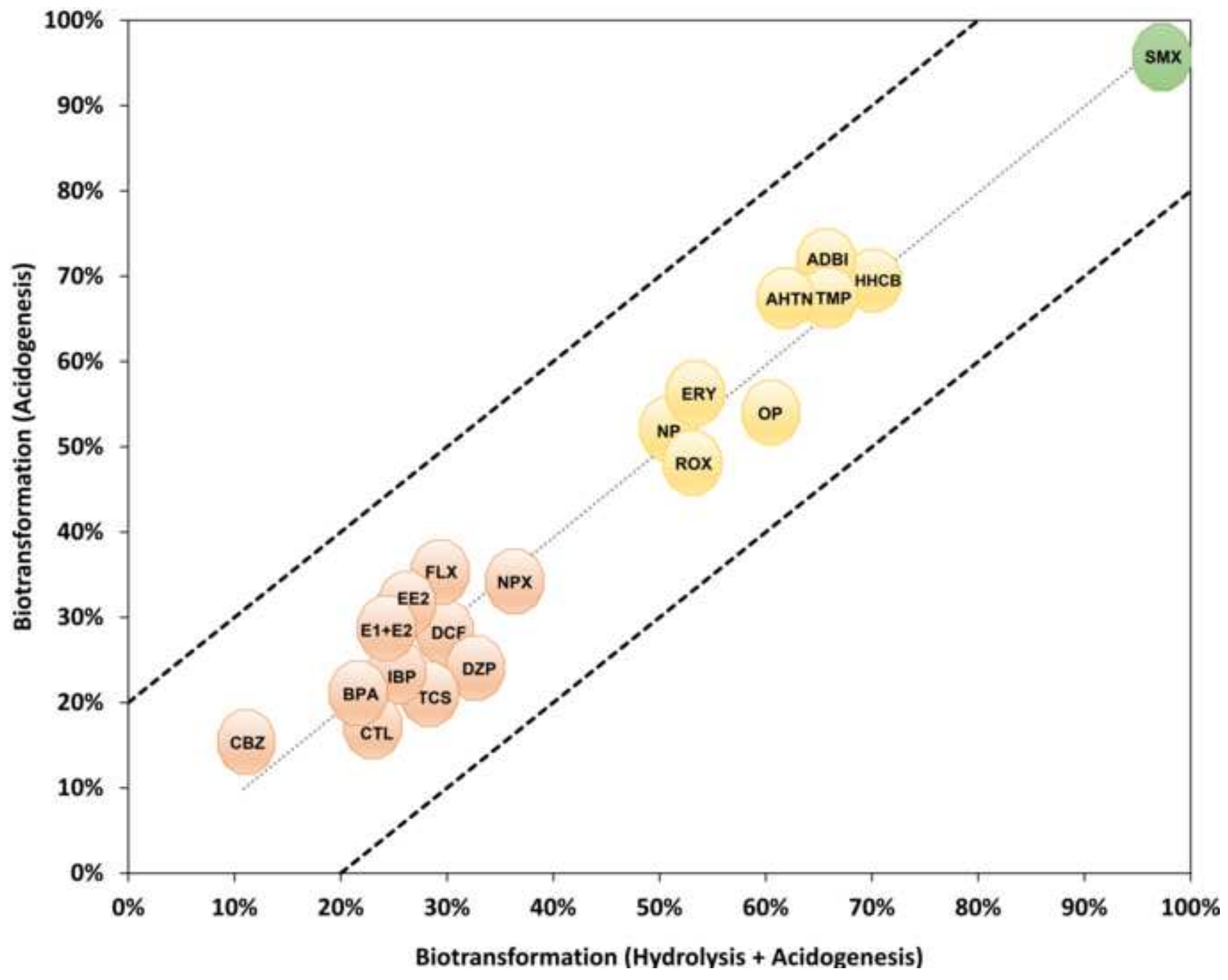




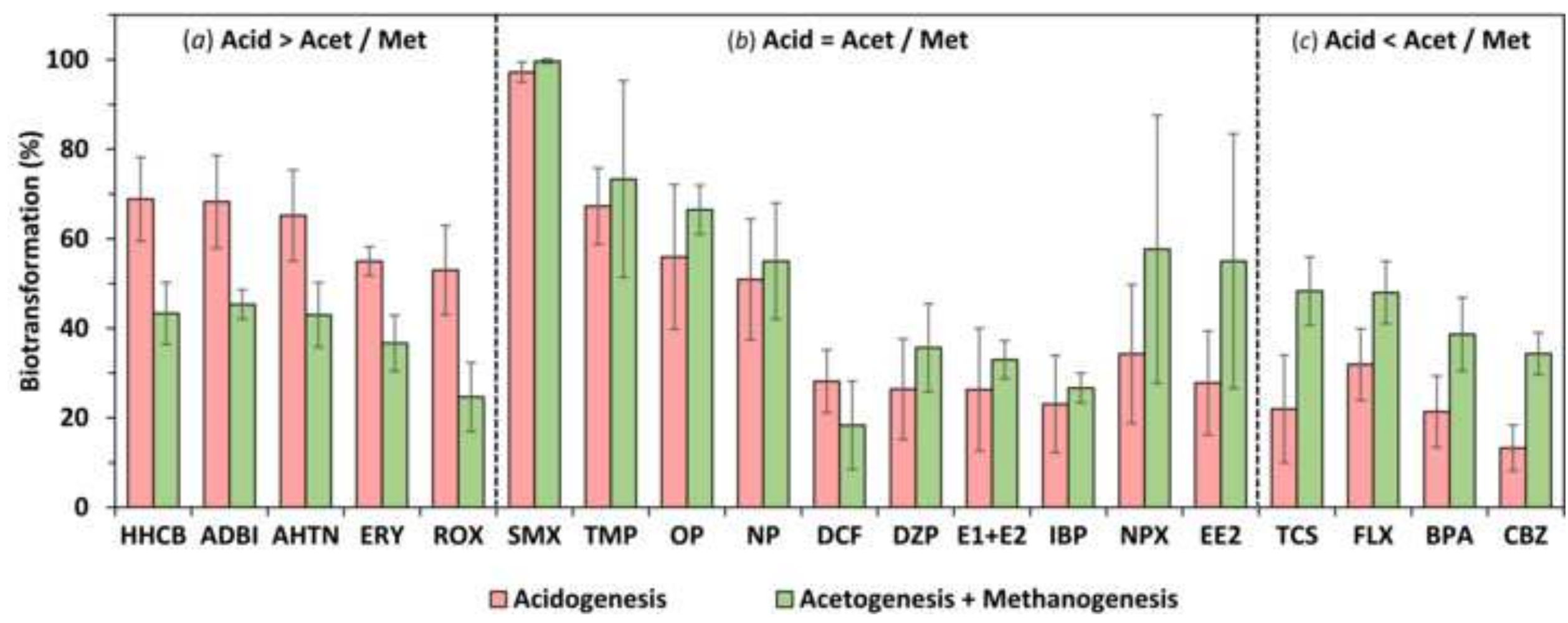

